\title{
Regression Models Utilization to the Underground Temperature Determination at Coal Energy Conversion
}

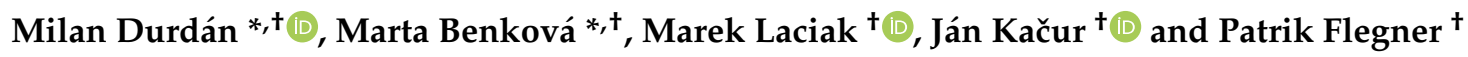 \\ Institute of Control and Informatization of Production Processes, Faculty of Mining, Ecology, Process Control and \\ Geotechnologies, Technical University of Košice, Němcovej 3, 04200 Košice, Slovakia; \\ marek.laciak@tuke.sk (M.L.); jan.kacur@tuke.sk (J.K.); patrik.flegner@tuke.sk (P.F.) \\ * Correspondence: milan.durdan@tuke.sk (M.D.); marta.benkova@tuke.sk (M.B.); Tel.: +421-55-602-5178 (M.D.) \\ + These authors contributed equally to this work.
}

Citation: Durdán, M.; Benková, M.; Laciak, M.; Kačur, J.; Flegner, P. Regression Models Utilization to the Underground Temperature Determination at Coal Energy Conversion. Energies 2021, 14, 5444. https://doi.org/10.3390/en14175444

Academic Editors: Adam Smoliński and Sarma V. Pisupati

Received: 20 July 2021

Accepted: 26 August 2021

Published: 1 September 2021

Publisher's Note: MDPI stays neutral with regard to jurisdictional claims in published maps and institutional affiliations.

Copyright: (c) 2021 by the authors. Licensee MDPI, Basel, Switzerland. This article is an open access article distributed under the terms and conditions of the Creative Commons Attribution (CC BY) license (https:/ / creativecommons.org/licenses/by/ $4.0 /)$.

\begin{abstract}
The underground coal gasification represents a technology capable of obtaining synthetic coal gas from hard-reached coal deposits and coal beds with tectonic faults. This technology is also less expensive than conventional coal mining. The cavity is formed in the coal seam by converting coal to synthetic gas during the underground coal gasification process. The cavity growth rate and the gasification queue's moving velocity are affected by controllable variables, i.e., the operation pressure, the gasification agent, and the laboratory coal seam geometry. These variables can be continuously measured by standard measuring devices and techniques as opposed to the underground temperature. This paper researches the possibility of the regression models utilization for temperature data prediction for this reason. Several regression models were proposed that were differed in their structures, i.e., the number and type of selected controllable variables as independent variables. The goal was to find such a regression model structure, where the underground temperature is predicted with the greatest possible accuracy. The regression model structures' proposal was realized on data obtained from two laboratory measurements realized in the ex situ reactor. The obtained temperature data can be used for visualization of the cavity growth in the gasified coal seam.
\end{abstract}

Keywords: underground coal gasification; measurement; temperature; regression; model; analyses; cavity

\section{Introduction}

The underground coal gasification process (i.e., the UCG process) is a constantly evolving technology and provides an alternative to conventional coal mining. This technology transforms coal into high-calorific gas (i.e., syngas), and for coal mines located in great depths is especially effective. In implementing this technology, at least one injection and one production well must be drilled from the earth's surfaces in an area where the coal seam is located. A gasification agent (i.e., the ratio of air, oxygen, and water vapor) is injected through the injection well. This gasification agent will ensure the chemical reactions occur. These chemical reactions are required for the syngas creating. Subsequently, Syngas is extracted through the production well and subsequently cleaned and stored (see Figure 1).

The UCG reactor can be divided into three basic zones in terms of the chemical reactions that occur. Chemical reactions to increase the coal seam temperature are taking place in the oxidation zone (i.e., at a temperature above $900^{\circ} \mathrm{C}$ ). In the reduction zone (i.e., at a temperature between $550-900{ }^{\circ} \mathrm{C}$ ), chemical reactions transform coal into syngas (i.e., a mixture of $\mathrm{CO}, \mathrm{CO}_{2}, \mathrm{CH}_{4}, \mathrm{H}_{2}$, etc.). The pyrolysis and drying process of the coal seam takes place in the drying and pyrolysis zone (i.e., at a temperature between $220-550{ }^{\circ} \mathrm{C}$ ). All these processes take place at a desired coal seam temperature. It is important to know the temperature distribution in the coal seam for this reason. The temperature information can determine the distribution of the individual zones in the coal seam and set the appropriate gasification agent mixture to increase the coal seam temperature or create syngas. In 
addition, the cavity formation process in coal seam can be observed by seeing behaviors of temperatures [1,2].

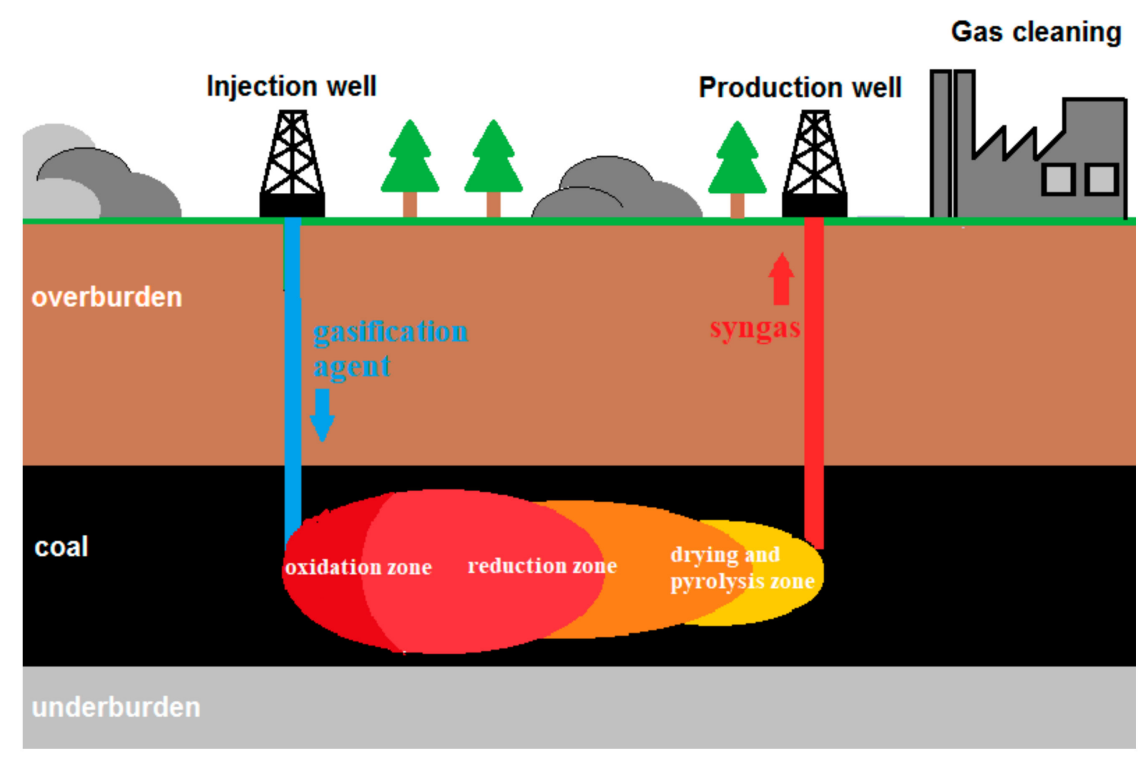

Figure 1. The scheme of the UCG process (Source: own elaboration).

Model in the form of a risk graph and a risk matrix was used for risk analysis and hazard identification in the UCG process by investigating health risks and impacts in terms of their influence on the environment [3]. The proposed measures could lead to the reduction of risks and impacts on an acceptable level. The UCG process state prediction was realized by a dual-source long short-term memory (i.e., LSTM) prediction model [4]. This model was compared with the Support Vector Machine (i.e., SVM) and Back Propagation Neural Network (i.e., BPNN) prediction model. The results showed that the predicting trends accuracy reaches $90.99 \%$. The prediction of syngas composition was realized by a thermochemical equilibrium model of the UCG process [5]. This model considers the effect of the drying process and is based on the water-gas shift reaction and gasification reactions. The results showed the positive impact of the steam addition into the gasification agent to increase the hydrogen and carbon monoxide content in syngas and increase the calorific value. A stoichiometric equilibrium model has been used to estimate the equilibrium composition of the produced gas [6]. This model is based on the Gibbs function's minimization and was used to simulate the relevant thermochemical coal conversion processes. Verification of described model showed that the produced gas composition was in a good agreement under different operating conditions. A three-dimensional numerical model has been used to simulate an ex situ allothermal coal gasification experiment [7]. The deviations between the simulated composition of produced gas and experimental data were from $10 \%$ (e.g., $\mathrm{H}_{2}$ ) to less than $50 \%$ (e.g., $\mathrm{CH}_{4}$ ) at some coal samples. The prediction of the shape and volume of the underground cavity over time was realized by the model based on a series of equations, the cavity pressure, and temperature information [8]. The simulations were realized by COMSOL software, and the results in the form percentage of the product gas components (i.e., $\mathrm{CO}, \mathrm{CO}_{2}, \mathrm{CH}_{4}$, and $\mathrm{H}_{2}$ ) showed a good comparison. A review of various gasification UCG models for predicting the cavity growth and the product gas recovery where the temperature value (i.e., the cavity temperature, solid-phase temperature, the gasification agent temperature, and the produced gas temperature) has the critical role was described [9]. The results of this review showed that the packed bed models are applicable for highly permeable porous media, the channel models overcome the limitation of the packed bed models in regards to calculating the cavity shape and size, and the coal slab models describe the process by the movement of the various defined regions in the coal slab. An empirical model based on the non-linear multivariable regression method 
also realized the prediction of cavity growth [10]. Nine possible independent variables as moisture, operating pressure, seam thickness, seam depth, calorific value, permeability, volatile matter, and fixed carbon were evaluated in terms of their prediction ability during the analysis. The regression analysis excluded the coal seam thickness and fixed carbon content. The investigation of reaction zones, reaction rates, cavity formation, and syngas properties was made by a two-dimensional computational fluid dynamics model [11]. This model was verified by numerical calculation of the syngas composition and a lab-scale hydrogen experiment. A good agreement was shown between the calculated and the experimental data at every stage. A laboratory-based UCG model with advanced real-time control and monitoring was used for monitoring cavity formation, temperatures, syngas characteristics, and coal-tar [12]. Results showed the ability of the laboratory-based UCG process to forecast the sustainability and standardization before the UCG process implementation by observed of the realized experiment. It has been demonstrated a significant influence of operational pressure and coal properties on the process parameters as energy efficiency, gas composition, and methane yields by realized model experiments [13]. The oscillations of the gas production rates reflected the changes in gasification conditions and the cavity geometry. A dependence was shown of methane yields on the properties of coal and the pressure regime. The Continuous Retracting Injection Point (i.e., CRIP) Process Model and the Linked Vertical Wells (i.e., LVW) Process Model were used for modeling the rate of cavity growth and the related chemical process in the UCG process [14]. The CRIP Process Model showed the more controllable cavity growth rate in a better-regulated water influx from the surrounding strata.

Nowadays, it is of great interest in the methods area which examining temperatures distribution in the coal seam. The temperature field calculation was solved by two-dimension nonlinear unstable mathematical models and analyzing the regularity of the temperature field distribution in the gasified coal layers of the UCG reactor [15]. The laboratory model experiment in a laboratory gasifier was used to establish the accuracy of this methodology. The most significant differences between calculated results and measured temperatures were in the combustion zone (i.e., some temperature points above $20 \%$ ), but differences of other measuring points are below $15 \%$, most of which, within $10 \%$. The analytical solution of one-dimensional unsteady heat conduction was used to study temperature distribution in burnt surrounding rocks at the UCG process [16]. The heat conduction is solved by the first and the fourth kinds of boundary conditions in this solution. The modeled case showed that the temperature influence range in burnt surrounding rock is circa 18-19 $\mathrm{m}$. The two-dimensional temperature field of the UCG reactor was also solved by the heat conduction model based on the first and third kinds of boundary conditions and velocity of motion of the gasification front [17]. There was examined the influence of burned coal seam (i.e., the heat source) on surroundings rocks, including the earth surface. The modeled cases showed that the temperature changes of the surrounding rock were maximal $14 \mathrm{~m}$ from the boundary of the coal and overburden towards the earth's surface. A mathematical prediction model using the CFD software package (FLUENT 6.3.26) was used to predict cavity growth, temperature distribution, and coal consumption [18]. The CFD software package solved the simulation of combustion and gasification reactions on the interface between the coal seam and cavity. The error of the coal consumption prediction was less than 5\%. During the underground coal gasification process, the temperature change in rock strata was identified in the numerical simulation based on the computational fluid dynamics formalism [19]. The applied software allowed the creation of coal gasification processes models at different conditions and, mainly, the process occurring beneath the ground surface. The modeled study showed temperature changes from 0.5 (i.e., $1000{ }^{\circ} \mathrm{C}$ ) to 2.5 (i.e., $75^{\circ} \mathrm{C}$ ) meters above the gasification channel. Thermo-mechanical simulations were used to quantify the permeability changes in representative coal measure strata surrounding the UCG reactor [20]. The influence of the temperature-dependent and temperature-independent rock properties on the spatial permeability development was 
compared in this study. The results showed that temperature-dependent parameters are required for simulations in the close vicinity of the reactor.

Various statistical methods are used to predict values in the UCG process, including regression analysis. Regression analysis is a powerful statistical method that researchers widely use to examine the relationship between two or more variables of interest. The differential equation based on linear regression was developed to modeling the carbon dioxide emission data [21]. The penalized least-square fitting criteria were used to smooth the data. Optimizing the profile error sum of squares was used for the estimation of differential operators using functional regression. The logistic regression model from four statistical models reached the highest probability of predicting future pipe accidents [22] It was shown that the most effective variables are the length, diameter, material, and hydraulic pressure in the pipe failure areas. The vector regression method was used for modeling the coal gross calorific value [23]. This method showed that carbon, moisture, ash, and hydrogen contents in the coal are the most effective variables for the gross calorific value modeling. The correlation of determination (R-2) for models was 0.99. Several statistical approaches solved the online coal calorific value prediction based on the flame radiation features in linear and nonlinear regression analyses [24]. The partial least squares analysis-based nonlinear regression model showed the best performance for coal calorific value prediction. The regression model is also used to calculate the pulverized coal ignition temperature [25]. The results showed that the multivariate regression method is useful for determining the ignition temperature calculation formula. Multivariable regression and artificial neural network methods were used for a wide range of coal samples from a calorific value of 10.05 to $34.80 \mathrm{MJ} / \mathrm{kg}$ [26]. The correlation coefficient values $0.77,0.75$, and 0.81 were reached by the least square mathematical method at the investigation of the relationship between inputs parameter (i.e., moisture, volatile matter, ash, total sulfur, etc.) and HGI (i.e., Hardgrove Grindability Index) in linear condition. A multivariate adaptive regression splines (i.e., MARS) approach was used for predicting the syngas temperature [27]. This proposed approach was tested in the fire prevention area of UCG processes. The effect of the coal rank to examine the composition and toxicity of water effluents was solved by statistical analysis [28]. The principal component analysis, Pearson correlation analysis, and the multiple regression statistical method were used to predict the toxicity using the values of the selected parameters. The proposed regression model had a high coefficient of determination $\mathrm{R}^{2}=0.956$ to experimental data. The study for identifying physicochemical parameters of river water that affect the electrical conductivity and evaluate their percentage contribution was realized [29]. The correlation coefficients calculation and display of the various parameters regression equations with electrical conductivity were realized by statistical analysis in this study. It is found that total dissolved solids have the highest contribution (39.6\%) while total alkalinity has the second-highest contribution (23.5\%), followed by total hardness (19.9\%). A multiple regression model was proposed for a real-time surface roughness prediction system [30]. The proposed models with linear correlation coefficients of 0.940 and 0.933 for predictor variables, such as feed rate, vibration amplitude average, spindle speed, and depth of cut, had a strong linear correlation with the predicted variable. The regression model had an accuracy of above $90 \%$ in predicting the surface roughness. A new data mining algorithm has been proposed to capture the non-linearity in data and also find the best subset model [31]. This proposed algorithm based on the classical least square regression framework is compared with the five nodes of the neural network method. The correlation coefficient was 0.79 in the proposed algorithm and 0.81 in the neural network method. The UCG data prediction in laboratory conditions was realized by the utilization support vector machines method [32] This method analyzed data used for classification and regression analysis to predict the underground temperature and syngas calorific value. The results obtained from the Matlab program and its statistical toolbox showed that the most appropriate is to use the Gaussian kernel function to achieve the best prediction quality. Statistical data processing was realized to investigate the relationships between measured quantities during the 
atmospheric geochemical survey of contaminated soil and the environmental burden of the industrial establishment [33]. The dependency between examined values was confirmed by regressive and correlative analysis.

It is necessary to continue to develop methods that would improve the prediction of the UCG process state in its implementation process due to the specificity of this process, mainly its diversity, which is determined by different geological environments. This improvement includes the accuracy improvement of the underground temperature calculation, which leads to the achievement of the required behavior of chemical reactions, the range determination of the surrounding rock burning, the prediction of cavity growth, and the produced gas's composition determination. It could lead to an increase in the efficiency of this process by producing gas with the highest possible calorific value (i.e., obtaining the maximum amount of energy) in the process control while minimizing the negative impact on the environment. We focused on using regression analysis methods to model the temperatures of the gasified coal seam in an ex situ reactor due to the wide range of applications of regression analysis methods in the processes of extraction and processing raw material. For this goal, two experiments with the same structure of the coal model differed by the amount of gasified coal were performed. Regression models were created from the data of the first experiment and subsequently verified on the data from the second experiment. Verification of the suitability of the created regression models for their use in different conditions was performed, i.e., a different amount of gasified coal and thus also different amounts of gasification agent and a time of the experiment.

\section{Experiments Methodology}

The methodology of the UCG process physical modeling in experimental equipment is widely used by researchers (e.g., in [34,35]). For this reason, an experimental gasifier was designed and constructed to realize the UCG process experimental measurements. The UCG process experiments were performed in an experimental laboratory gasifier (i.e., ex situ reactor). This ex situ reactor has a length of $3000 \mathrm{~mm}$ and a height of $500 \mathrm{~mm}$ and comprises two basic parts, i.e., a vessel and lid. The ex situ reactor vessel is semi-cylindrical in shape and consists of the vessel jacket and the forehead (i.e., front and rear). The inner surface of the ex situ reactor vessel is covered $100 \mathrm{~mm}$ thick in the isolation, which is placed under the steel cover plate. The scheme of the experimental coal gasification system is shown in Figure 2. A fan was placed behind the reactor vessel to direct the flow of the gasification agent through the coal model.

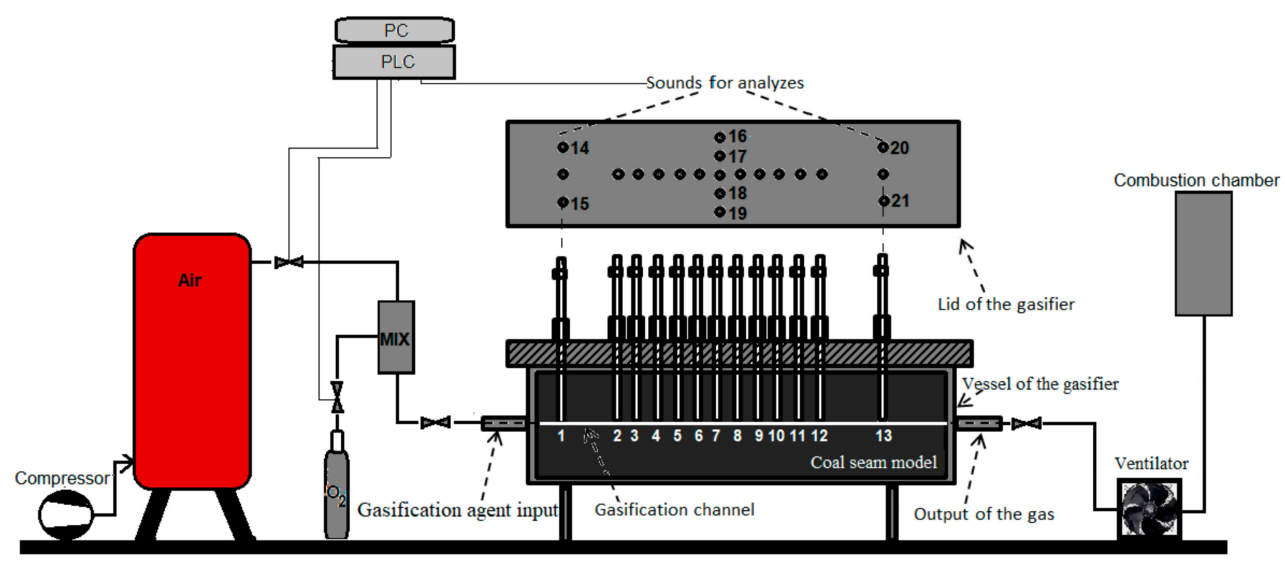

Figure 2. Scheme of the experimental coal gasification system (Source: own elaboration).

The coal seam model embedded into the ex situ reactor included the overburden, underburden, and coal blocks. This model was arranged so that the gasification agent could permeate through the whole coal seam model (i.e., the gasification channel was drilled through the entire coal seam model). The experiments were based on the regulated 
supply of the gasification agent (i.e., through the gasification agent input) into burning the coal seam model (i.e., embedded into the ex situ reactor) and exhaust of the syngas (i.e., through the output of the gas). The gasification agent composition was set by the ratio of the air and the oxygen (i.e., $\mathrm{O}_{2}$ ). The syngas composition consisted of the following components ratio, i.e., the carbon monoxide (i.e., $\mathrm{CO}$ ), the oxygen, the methane (i.e., $\mathrm{CH}_{4}$ ), the hydrogen (i.e., $\mathrm{H}_{2}$ ), etc. The syngas extraction and temperature measurement were realized by sounds placed on the ex situ reactor lid. Thermocouples measured the channel and coal temperatures, i.e., thirteen thermocouples were placed in the gasification channel (i.e., 1-13 sounds), and eight thermocouples were placed in the coal (i.e., 14-21 sounds).

Measured values, i.e., channel and coal temperatures, gasification agent and syngas composition, and their flows, were transferred from the ex situ reactor to the PC. These values were processed and shown by the monitoring system. The control of the UCG process was based on the evaluation of these values by the control algorithm. Two experiments in the described experimental ex situ reactor were realized for the regression modeling of the measured temperature values.

\subsection{The First Experiment}

The one layer of coal cubes with a total weight of $214 \mathrm{~kg}$ was embedded into the ex situ reactor. This layer had circa $30 \mathrm{~cm}$ the width and circa $25 \mathrm{~cm}$ the height. The technical analysis of these coal samples was carried in an accredited laboratory, and its results are shown in Table 1. The individual coal blocks were glued with a mixture of gudron, coal dust, and water. The cross-sectional design of the coal seam model for this experiment is shown in Figure 3. A gasification channel along the length of the whole ex situ reactor was created in the bottom third of the coal seam model height (see Figure 4a). The gasification channel had a diameter of $20 \mathrm{~mm}$. The coal blocks layer was covered with a thermal insulation foil because of the prevention of heat leakage at the UCG process (see Figure $4 b$ ).
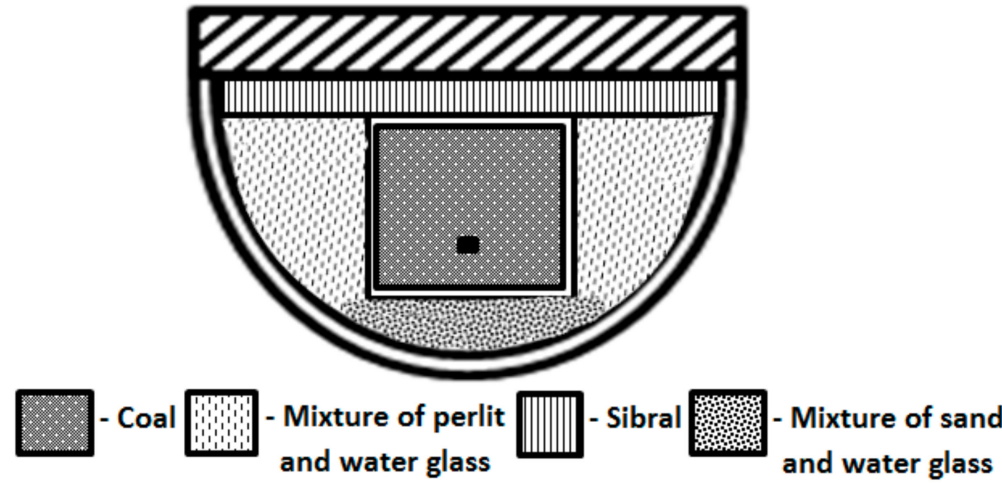

Figure 3. The cross-sectional designs of the coal model for the first experiment (Source: own elaboration based on [36]).
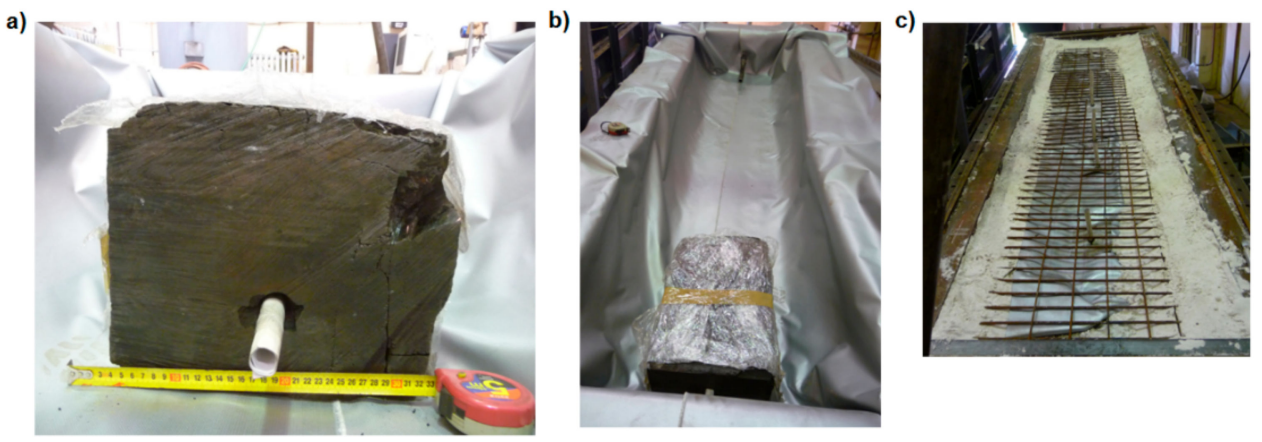

Figure 4. The construction of the coal model (a) gasification channel placement, (b) thermal insulation of coal blocks, (c) reinforcement of coal model top part (Source: own elaboration). 
Table 1. The analysis of coal with the help of Slovak testing standards used by an accredited laboratory (Abbreviations: r-received, d-dry, daf-dry, ash-free, a-analytical, G-Gravimetry, EA-elementary analysis with heat conductive detector, K-Calorimetry, RFS-X-ray fluorescence spectrometry) (Source: own elaboration).

\begin{tabular}{|c|c|c|c|c|}
\hline Parameter & Value & Uncertainty & Method & Standard \\
\hline Total Moisture $W_{t}^{r}(\%)$ & 38.2 & 5 & G & PN 16.3 \\
\hline $\operatorname{Ash} A^{d}(\%)$ & 9.4 & 2 & G & PN 16.4 \\
\hline Volatiles $V^{\text {daf }}(\%)$ & 50 & 4 & G & PN 16.2 \\
\hline Carbon $C^{\text {daf }}(\%)$ & 76.5 & 2 & EA & PN 16.7 \\
\hline Hydrogen $H^{\text {daf }}(\%)$ & 3.95 & 5 & EA & PN 16.7 \\
\hline Nitrogen $N^{\text {daf }}(\%)$ & 1.48 & 40 & EA & PN 16.7 \\
\hline Calorific Value $Q_{i}^{\text {daf }}(\mathrm{MJ} / \mathrm{kg})$ & 30.2 & 2 & K & PN 16.2 \\
\hline Calorific Value $Q_{i}^{d}(\mathrm{MJ} / \mathrm{kg})$ & 27.4 & 2 & K & PN 16.1 \\
\hline Calorific Value $Q_{i}^{r}(\mathrm{MJ} / \mathrm{kg})$ & 16.0 & 2 & K & PN 16.1 \\
\hline $\operatorname{Ash} A^{r}(\%)$ & 5.81 & 2 & G & PN 16.4 \\
\hline Carbon $C^{r}(\%)$ & 42.8 & 2 & EA & PN 16.7 \\
\hline Hydrogen $H^{r}(\%)$ & 2.21 & 5 & EA & PN 16.7 \\
\hline Nitrogen $N^{r}(\%)$ & 0.83 & 20 & EA & PN 16.7 \\
\hline $\mathrm{CaO}(\%)$ & 2.37 & 5 & RFS & PN 3.1 \\
\hline $\mathrm{MgO}(\%)$ & 0.46 & 10 & RFS & PN 3.1 \\
\hline $\mathrm{SiO}_{2}(\%)$ & 1.23 & 10 & RFS & PN 3.1 \\
\hline $\mathrm{Al}_{2} \mathrm{O}_{3}(\%)$ & 0.74 & 10 & RFS & PN 3.1 \\
\hline $\mathrm{Fe}_{2} \mathrm{O}_{3}(\%)$ & 1.02 & 10 & RFS & PN 3.1 \\
\hline $\mathrm{Na}_{2} \mathrm{O}(\%)$ & $<0.2$ & & RFS & PN 3.1 \\
\hline $\mathrm{P}_{2} \mathrm{O}_{5}(\%)$ & $<0.02$ & & RFS & PN 3.1 \\
\hline $\mathrm{TiO}_{2}(\%)$ & 0.02 & 10 & RFS & PN 3.1 \\
\hline $\mathrm{K}_{2} \mathrm{O}(\%)$ & 0.06 & 10 & RFS & PN 3.1 \\
\hline Volatiles $V^{r}(\%)$ & 28 & 4 & G & PN 16.2 \\
\hline Analytical Moisture $W^{a}(\%)$ & 21.5 & 5 & G & PN 16.3 \\
\hline Total Sulphur $S_{t}^{r}(\%)$ & 1.62 & 15 & G & PN 16.5 \\
\hline Sulphate Sulphur $S_{S}^{r}(\%)$ & 0.17 & 15 & G & PN 16.5 \\
\hline Pyritic Sulphur $S_{p}^{r}(\%)$ & 0.99 & 15 & G & PN 16.5 \\
\hline Organic Sulphur $S_{o}^{r}(\%)$ & 1.44 & 15 & G & PN 16.5 \\
\hline
\end{tabular}

The thermal insulation foil separated coal blocks and a mixture of perlit and the water glass. The mixture of perlit and the water glass created isolation around the top and sides of the coal blocks. The inner bottom part of the ex situ reactor was covered with a mixture of sand and water glass. The top part of the isolation was reinforced with the steel construction because of the prevention of the isolation fall after combustion of coal blocks (see Figure 4c). The sibral plate was placed over the top part of the insulation. The mixture of perlit and the water glass, the mixture of the sand and the water glass, and sibral simulated the surrounding rock of the coal seam. The analysis shown in Figure 5 confirmed that whole coal blocks were burned.

\subsection{The Second Experiment}

The ex situ reactor was filled with a layer of coal cubes in a total weight of $472 \mathrm{~kg}$ for this experiment. The same type of coal was used as in the first experiment, i.e., coal composition is shown in Table 1. The coal seam model with the isolation around had a similar shape as is shown in Figure 3, but the gasification channel had a diameter of $40 \mathrm{~mm}$. The coal blocks were cemented by a mixture of gudron, coal dust, and water (see Figure 6).

The thickness of the unburnt coal was different along the whole ex situ reactor length. In the first meter, the thickness of the unburnt coal was about 3-4 cm, in the second meter, it was around 4-6 cm (see Figure 7a), and in the third meter, it was about 6-8 cm at the edges even more, up to $16 \mathrm{~cm}$ as is shown in Figure $7 \mathrm{~b}$. There was $66 \mathrm{~kg}$ of unburned coal that is circa $14 \%$ from input coal. 


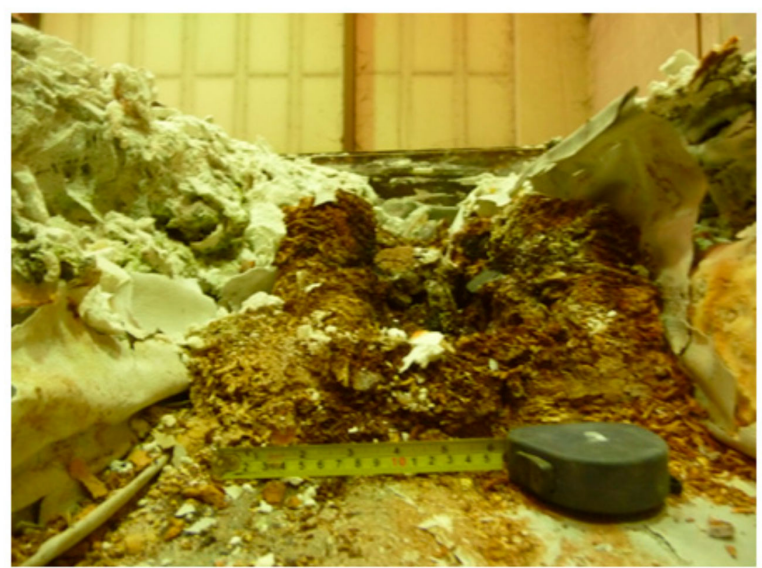

Figure 5. The coal blocks in the experimental generator after the gasification process (Source: own elaboration.

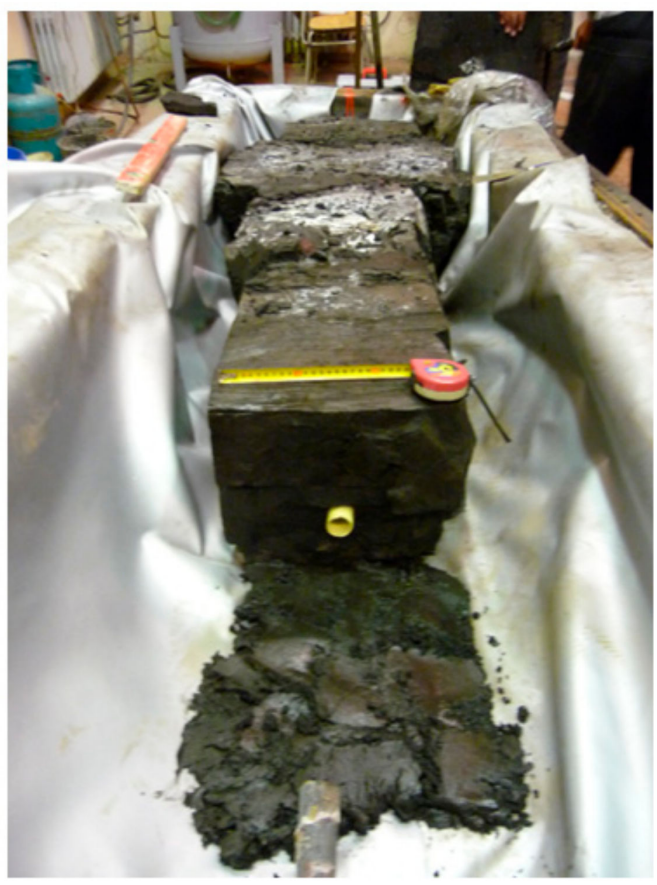

Figure 6. The coal blocks cemented to each other by a mixture of gudron (Source: own elaboration).

a)

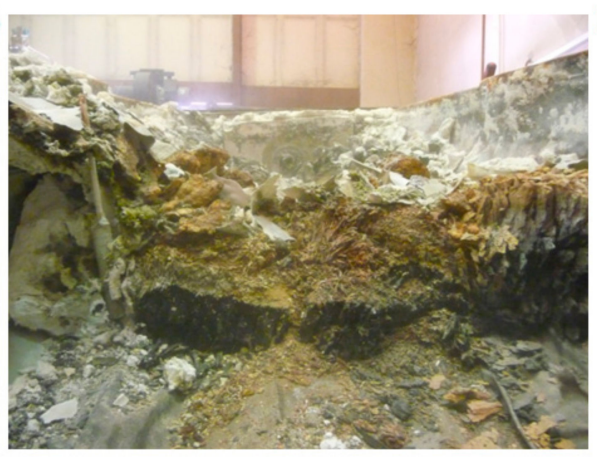

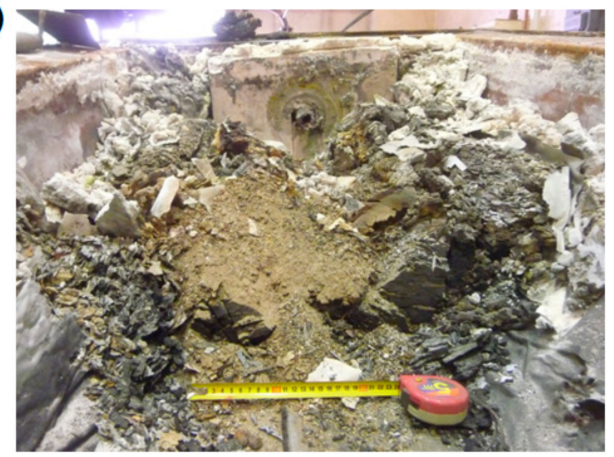

Figure 7. The unburned layer of coal (a) in the second meter, (b) in the third meter (Source: own elaboration). 


\section{Regression Methodology}

It is often necessary to take into account that one dependent variable $y$ is affected by several independent variables $x_{1} x_{2}, \ldots, x_{k}$ [37]. We can write it in the following form:

$$
y=\beta_{0}+\beta_{1} x_{1}+\beta_{2} x_{2}+\ldots+\beta_{k} x_{k}+\varepsilon,
$$

where the regression parameter $\beta_{j} j=1,2, \cdots, k$, expresses the assumed change in the variable $y$ caused by the unit change of one independent variable $x_{j}$, if the other independent variables do not change; $\varepsilon$ is a random error.

The least-squares method is most often used to estimate the regression parameters of multiple linear regression models. The least-squares method requires $n$ observations of all considered independent variables $x_{j} j=1,2, \ldots, k$, i.e., $x_{i j} i=1,2, \ldots, n$, [38]. We will assume that the variables $\varepsilon_{i}$ are uncorrelated random variables with zero mean value, and constant variance. Then, Equation (1) can be written in a modified form using the data from Table 2:

$$
y_{i}=\beta_{0}+\beta_{1} x_{i 1}+\beta_{2} x_{i 2}+\cdots+\beta_{k} x_{i k}+\varepsilon_{i}=\beta_{0}+\sum_{j=1}^{k} \beta_{j} x_{i j}+\varepsilon_{i}, \text { for } i=1,2, \ldots, n
$$

Table 2. Data for multiple linear regression [38].

\begin{tabular}{lllll}
\hline$y$ & $x_{1}$ & $x_{2}$ & $\ldots$ & $x_{k}$ \\
$y_{1}$ & $x_{11}$ & $x_{21}$ & $\ldots$ & $x_{1 k}$ \\
$y_{2}$ & $x_{21}$ & $x_{22}$ & $\ldots$ & $x_{2 k}$ \\
$\vdots$ & $\vdots$ & $\vdots$ & & $\vdots$ \\
$y_{n}$ & $x_{n 1}$ & $x_{n 2}$ & $\ldots$ & $x_{n k}$ \\
\hline
\end{tabular}

We can formulate the object function $L$ for the least-squares method of the model (2) in the form that ensures that the sum of squares of errors $\varepsilon_{i}$ is minimized, i.e.,:

$$
L=\sum_{i=1}^{n} \varepsilon_{i}^{2}=\sum_{i=1}^{n}\left(y_{i}-\beta_{0}-\sum_{j=1}^{k} \beta_{j} x_{i j}\right)^{2}
$$

The object function $L$ must be minimized in respect of the parameters $\beta_{0}, \beta_{1}, \cdots \beta_{k}$. It can be written in the form of equations:

$$
\left.\frac{\partial L}{\partial \beta_{0}}\right|_{\hat{\beta}_{0}, \hat{\beta}_{1}, \ldots, \hat{\beta}_{k}}=-2 \sum_{i=1}^{n}\left(y_{i}-\hat{\beta}_{0}-\sum_{j=1}^{k} \hat{\beta}_{j} x_{i j}\right)=\left.0 \frac{\partial L}{\partial \beta_{j}}\right|_{\hat{\beta}_{0}, \hat{\beta}_{1}, \ldots, \hat{\beta}_{k}}=-2 \sum_{i=1}^{n}\left(y_{i}-\hat{\beta}_{0}-\sum_{j=1}^{k} \hat{\beta}_{j} x_{i j}\right) x_{i j}=0 j=1,2, \ldots, k
$$

The least-squares normal equations are obtained by simplifying Equations (4) into the form (5):

$$
\begin{gathered}
n \hat{\beta}_{0}+\hat{\beta}_{1} \sum_{i=1}^{n} x_{i 1}+\hat{\beta}_{2} \sum_{i=1}^{n} x_{i 2}+\cdots+\hat{\beta}_{k} \sum_{i=1}^{n} x_{i k}=\sum_{i=1}^{n} y_{i}, \\
\hat{\beta}_{0} \sum_{i=1}^{n} x_{i 1}+\hat{\beta}_{1} \sum_{i=1}^{n} x_{i 1}^{2}+\hat{\beta}_{2} \sum_{i=1}^{n} x_{i 1} x_{i 2}+\cdots+\hat{\beta}_{k} \sum_{i=1}^{n} x_{i 1} x_{i k}=\sum_{i=1}^{n} x_{i 1} y_{i} \\
\vdots \\
\vdots \\
\vdots \\
\hat{\beta}_{0} \sum_{i=1}^{n} x_{i k}+\hat{\beta}_{1} \sum_{i=1}^{n} x_{i k} x_{i 1}+\hat{\beta}_{2} \sum_{i=1}^{n} x_{i k} x_{i 2}+\cdots+\hat{\beta}_{k} \sum_{i=1}^{n} x_{i k}^{2}=\sum_{i=1}^{n} x_{i k} y_{i}
\end{gathered}
$$

Subsequently, estimates of regression parameters $\beta_{0}, \beta_{1}, \cdots \beta_{k}$ are obtained by solving these equations. It is appropriate to use matrix notation to simplify the solution of equations:

$$
y=X \beta+\varepsilon
$$


where

$$
\boldsymbol{y}=\left[\begin{array}{c}
y_{1} \\
y_{2} \\
\vdots \\
y_{\mathrm{n}}
\end{array}\right], \boldsymbol{X}=\left[\begin{array}{ccccc}
1 & x_{11} & x_{12} & \cdots & x_{1 \mathrm{k}} \\
1 & x_{12} & x_{22} & \cdots & x_{2 \mathrm{k}} \\
\vdots & \vdots & \vdots & & \vdots \\
1 & x_{\mathrm{n} 1} & x_{\mathrm{n} 2} & \cdots & x_{\mathrm{nk}}
\end{array}\right], \boldsymbol{\beta}=\left[\begin{array}{c}
\beta_{0} \\
\beta_{1} \\
\vdots \\
\beta_{k}
\end{array}\right] \text { and } \boldsymbol{\varepsilon}=\left[\begin{array}{c}
\varepsilon_{1} \\
\varepsilon_{2} \\
\vdots \\
\varepsilon_{k}
\end{array}\right]
$$

Then, the vector of regression coefficient $\beta$ estimates is calculated as

$$
\hat{\boldsymbol{\beta}}=\left(\boldsymbol{X}^{T} \boldsymbol{X}\right)^{-1}\left(\boldsymbol{X}^{T} \boldsymbol{y}\right)
$$

and it can be used in notation of a multiple regression model

$$
\hat{y}=X \hat{\beta}
$$

or in the form

$$
\hat{y}_{i}=\hat{\beta}_{0}+\sum_{j=1}^{k} \hat{\beta}_{j} x_{i j}, i=1,2, \ldots, n
$$

The difference between the actual value $y_{i}$ and the corresponding modeled value $\hat{y}_{i}$ is called the residual.

$$
S S T=S S R+S S E,
$$

Furthermore, it is necessary to verify the suitability of the proposed multiple regression model. The first recommended test is a test to verify the existence of a linear regression relationship between the dependent variable $y$ and the selected independent variables. The null hypothesis $\mathrm{H}_{0}: \beta_{0}=\beta_{1}=\beta_{2}=\cdots=\beta_{k}=0$ will be tested against the alternative hypothesis $\mathrm{H}_{1}$ : Not all the $\beta_{i}, i=1,2, \cdots, k$ are zero. The test will use analysis of variance, the important calculations of which are shown in Table 3. The most important part of the test procedure is the calculation of the three sums of squares in the following form:

$$
\sum_{i=1}^{n}\left(y_{i}-\bar{y}\right)^{2}=\sum_{i=1}^{n}\left(\hat{y}_{i}-\bar{y}\right)^{2}+\sum_{i=1}^{n}\left(y_{i}-\hat{y}_{i}\right)^{2},
$$

Table 3. Analysis of variance for significance of regression in multiple regression [38].

\begin{tabular}{clllc}
\hline Source of Variation & \multicolumn{1}{c}{ Sum of Squares } & Degrees of Freedom & \multicolumn{1}{c}{ Mean Square } & F \\
\hline Regression & $S S R$ & $k$ & $M S R=S S R / k$ & $F=M S R / M S E$ \\
Error or residual & $S S E$ & $n-(k+1)$ & $M S E=S S E /(n-(k+1))$ & \\
Total & $S S T$ & $n-1$ & & \\
\hline
\end{tabular}

$\mathrm{H}_{0}: \beta_{0}=\beta_{1}=\beta_{2}=\cdots=\beta_{k}=0$ We will not reject if the calculated value of the test statistic $F$ is less than the critical value $F_{\alpha, k, n-k-1}$, or if the calculated $P$-value is greater than the selected level of significance of the test $\alpha$. If we do not reject the tested null hypothesis, there is no assumed linear relationship between the independent variable $y$ and the considered independent variables $x_{j} j=1,2, \cdots, k$. To verify the significance of individual independent variables, we can perform $\mathrm{t}$-tests. The null hypothesis has a form $\beta_{j}=0$ and is tested against the alternative hypothesis $\beta_{j} \neq 0$ for $j=1,2, \cdots, k$. The test statistic is calculated according to the formula:

$$
t=\frac{\hat{\beta}_{j}}{\sqrt{\hat{\sigma}^{2} C_{j j}}},
$$


Besides the estimated value of the coefficient $\hat{\beta}_{j}$, we also use the values of a standard error $\sqrt{\hat{\sigma}^{2} C_{j j}}$ where $C_{j j}$ are diagonal elements of the matrix $\left(\boldsymbol{X}^{T} \boldsymbol{X}\right)^{-1}$. We reject the null hypothesis if the value of the test statistic is greater than the critical value $t_{\alpha / 2, n-k-1}$ or if the $p$-value is less than the chosen level of significance $\alpha$. Because we want to evaluate the suitableness of a proposed multiple linear regression model, we use the mean square error-MSE defined as:

$$
M S E=\frac{S S E}{n-(k+1)},
$$

The lower the MSE values, the better the regression model expresses the measured data. The same is true for the square root of $M S E$, which is called the standard error of estimate and is marked s. Using the multiple coefficient of determination $R^{2}$, we can calculate the share of the variability of the dependent variable $y$, which is expressed by the model, i.e., a combination of selected independent variables used in the regression model. It can be written in the form:

$$
R^{2}=\frac{S S R}{S S T}=1-\frac{S S E}{S S T}
$$

At best, it is equal to $R^{2}=1$ or expressed in a percentage $R^{2}=100 \%$. We can use the adjusted multiple coefficient of determination $R_{a d j}^{2}$ to consider the number of independent variables in the proposed linear regression model. Thus, we take into account not only the values of $S S E$ and $S S T$, but also the numbers of freedom degrees $n-(k+1)$ and $(n-1)$ in this value calculation:

$$
R_{a d j}^{2}=1-\frac{\frac{S S E}{n-(k+1)}}{\frac{S S T}{n-1}}
$$

The comparison of the calculated values of $R^{2}$ and $R_{a d j}^{2}$ is also helpful from the point of view of considerations about the inclusion of individual independent variables in the multiple linear regression model. If their values differ significantly after the inclusion of a new variable, it is clear that the inclusion of this variable in the model is not necessary [39,40].

\section{Results and Discussion}

This chapter describes the proposal of multiple linear regression models for modeling temperatures in the gasification channel and in the coal, which are differed from each other in the number of independent variables considered. The coefficients of the proposed models were calculated by using the measured experimental data from the first experiment (see Section 2.1). Measured experimental data from the first experiment (i.e., the exhaust fan motor frequency, the flow of air and oxygen, and calorific value) are shown in Figure 8. Verification of the quality of the proposed models was performed on the measured data from this experiment by calculation of multiple coefficients of determination and standard error of the estimate. Furthermore, the change of experimental conditions was tested, i.e., the proposed models based on data of the first experiment were applied to the measured data from the second experiment (see Section 2.2), which were obtained under different conditions. Measured experimental data from the second experiment (i.e., the exhaust fan motor frequency, the flow of air and oxygen, and calorific value) are shown in Figure 9.

\subsection{The Proposal of a Multiple Linear Regression Model for the Channel's and Coal's Temperatures}

In the first stage of the solution, the kind of independent variables was chosen for the proposal of the temperature prediction model. These variables represent the measured variables: frequency of the fan located behind the ex situ reactor (see Figure 2), airflow, oxygen flow, syngas calorific value, temperatures measured in the channel and in coal. The models for the individual dependent variables-channel temperatures (i.e., $T_{j}^{\text {mod }}$ $j=3,4, \cdots, 13)$ differed by the selected measured temperatures in order from the place the coal seam ignition (i.e., gasification agent input) to the calculated temperature. For the model of the dependent variable temperature $T_{3}^{m o d}$, only the temperatures $T_{1}, T_{2}, T_{14}$, and $T_{15}$ were taken into account, but, e.g., for the temperature $T_{12}^{\text {mod }}$, all previously measured 
channel temperatures $T_{3}$ to $T_{11}$ were included in the model. The results of the correlation analysis (i.e., mainly calculations $R^{2}$ and $R_{a d j}^{2}$ coefficients) showed that temperatures measured in coal (i.e., temperatures $T_{16}, T_{17}, T_{18}, T_{19}, T_{20}, T_{21}$ ) are insignificant independent variables for the model proposal, and due to this reason, were excluded from the models. The mathematical form of the proposed regression models for channel's temperatures can be written in general form, as follows:

$$
T_{j}^{\text {mod }}=b_{0}+\sum_{i=1}^{7} b_{i} \cdot x_{i}+\sum_{i=8}^{i+j-3} b_{i} \cdot x_{i},
$$

where: $T_{j}^{\text {mod }}$ are modelled temperatures for $j=3,4, \cdots, 13\left({ }^{\circ} \mathrm{C}\right) ; x_{1}$ is frequency $(\mathrm{Hz}) ; x_{2}$ is airflow $\left(\mathrm{m}^{3} \cdot \mathrm{h}^{-1}\right) ; x_{3}$ is oxygen $\left(\mathrm{m}^{3} \cdot \mathrm{h}^{-1}\right) ; x_{4}$ is calorific value $\left(\mathrm{MJ} \cdot \mathrm{m}^{-3}\right) ; x_{5}$ is temperature $T_{1}\left({ }^{\circ} \mathrm{C}\right) ; x_{6}$ is temperature $T_{14}\left({ }^{\circ} \mathrm{C}\right) ; x_{7}$ is temperature $T_{15}\left({ }^{\circ} \mathrm{C}\right) ; x_{i}$ is temperature $T_{i-6}$ for $i=8,9, \cdots, 18\left({ }^{\circ} \mathrm{C}\right)$.

Measured data from the first experiment were used to determine the coefficients of multiple linear regression models. The calculations were performed in the Minitab statistical software using the least-squares method. The calculated coefficients of regression models for channel temperatures are shown in Table 4.

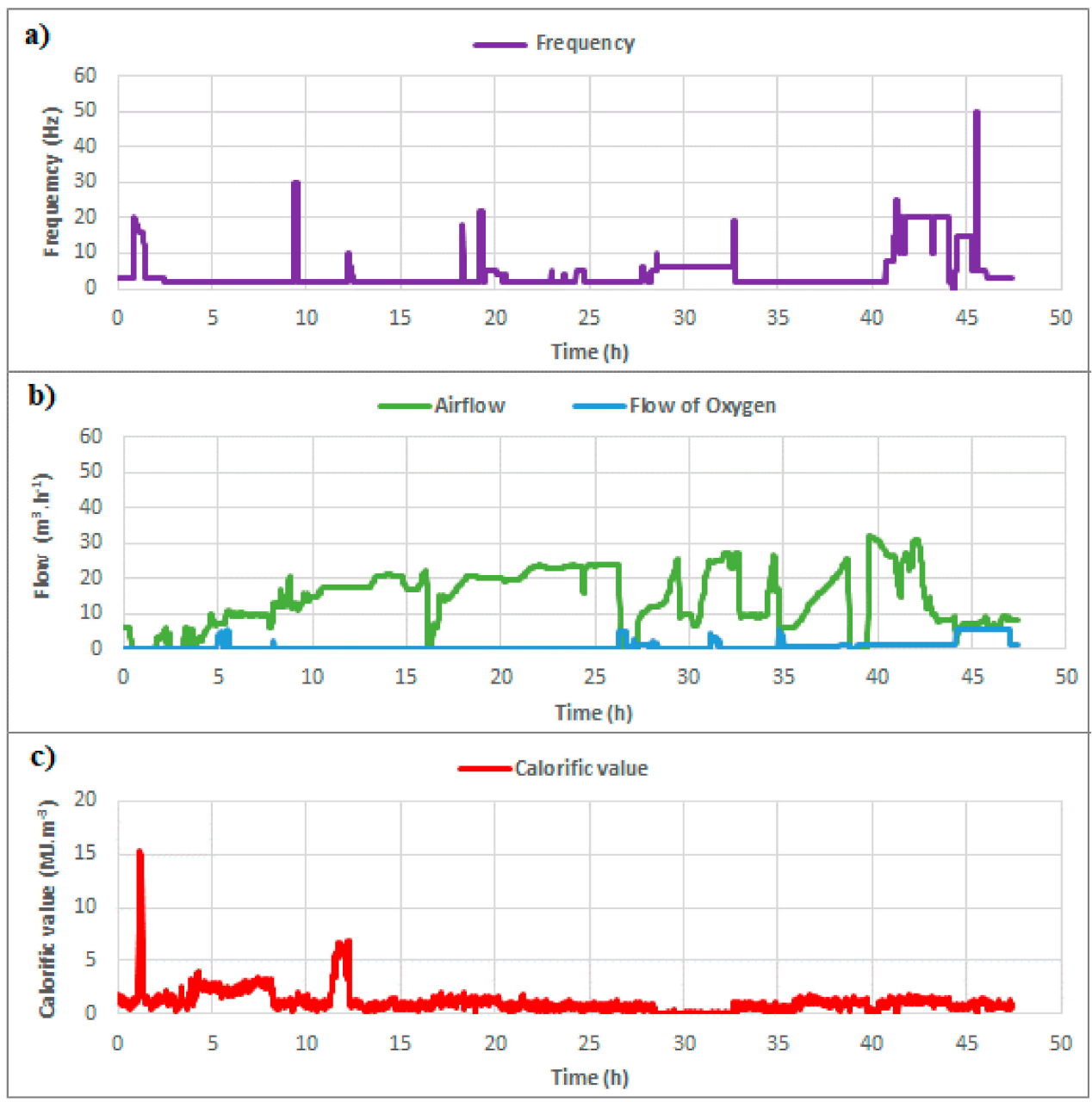

Figure 8. The measured data behaviors in the first experiment: (a) the exhaust fan motor frequency, (b) the air and oxygen, and (c) the calorific value (Source: own elaboration). 


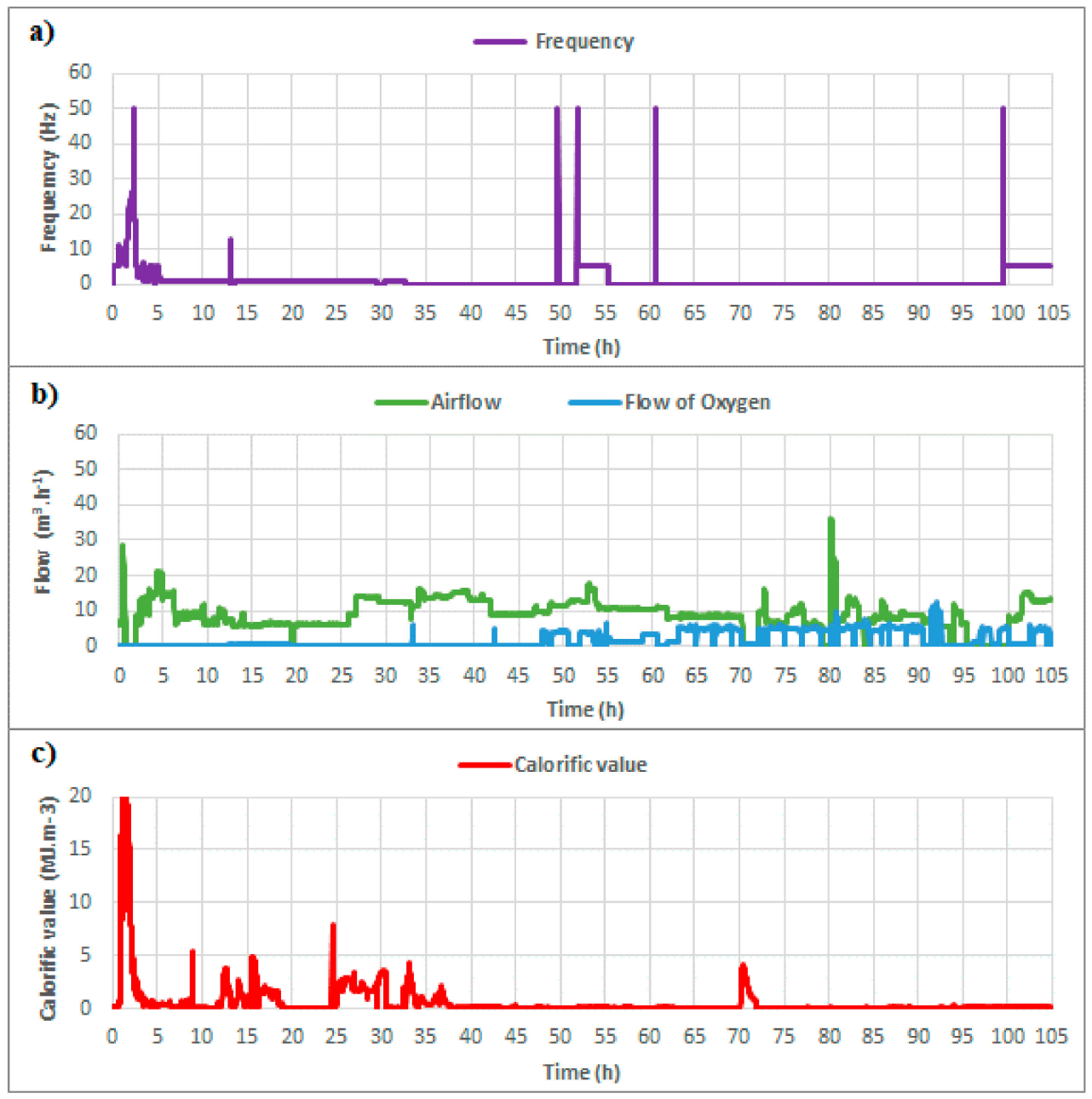

Figure 9. The measured data behaviors in the second experiment: (a) the exhaust fan motor frequency, (b) the air and oxygen, and (c) the calorific value (Source: own elaboration).

Table 4. Coefficients of regression models for channel temperatures and values of a multiple coefficient of determination and a standard error of the estimate (Source: own elaboration).

\begin{tabular}{|c|c|c|c|c|c|c|c|c|c|c|c|}
\hline Coefficients & $T_{3}^{m o d}$ & $T_{4}^{\text {mod }}$ & $T_{5}^{m o d}$ & $T_{6}^{m o d}$ & $T_{7}^{\text {mod }}$ & $T_{8}^{m o d}$ & $T_{9}^{m o d}$ & $T_{10}^{m o d}$ & $T_{11}^{\text {mod }}$ & $T_{12}^{\text {mod }}$ & $T_{13}^{m o d}$ \\
\hline$b_{0}$ & 122.473 & 67.662 & 38.014 & 15.472 & 4.003 & 96.044 & -24.393 & 88.273 & 71.571 & -17.614 & -28.813 \\
\hline$b_{1}$ & -0.824 & -0.287 & 0.352 & 0.519 & 0.314 & -0.250 & -0.002 & 1.218 & 0.038 & -1.027 & -0.109 \\
\hline$b_{2}$ & -1.821 & 1.339 & 1.141 & -0.684 & 0.127 & 1.239 & 0.068 & 2.759 & 0.077 & 2.409 & 0.193 \\
\hline$b_{3}$ & 8.895 & 8.739 & 2.781 & -0.569 & -1.390 & 2.237 & 0.042 & 4.450 & -0.298 & -2.911 & -0.255 \\
\hline$b_{4}$ & 1.617 & -4.234 & -0.241 & -2.720 & -0.051 & 4.504 & 0.143 & 0.369 & -3.353 & 2.398 & 0.092 \\
\hline$b_{5}$ & -0.419 & 0.173 & 0.052 & 0.063 & -0.056 & -0.208 & -0.011 & -0.726 & 0.155 & 0.170 & 0.015 \\
\hline$b_{6}$ & 0.210 & -0.106 & 0.035 & -0.052 & 0.117 & 0.038 & 0.001 & 0.403 & -0.227 & -0.187 & -0.020 \\
\hline$b_{7}$ & 0.174 & -0.005 & -0.099 & -0.042 & -0.022 & -0.003 & -0.002 & 0.128 & 0.026 & -0.001 & 0.000 \\
\hline$b_{8}$ & 0.936 & -0.082 & -0.055 & 0.279 & -0.040 & 0.070 & 0.001 & -0.146 & 0.197 & 0.030 & 0.006 \\
\hline$b_{9}$ & & 0.971 & 0.186 & -0.140 & -0.110 & 0.083 & 0.010 & 0.609 & -0.365 & -0.247 & -0.023 \\
\hline$b_{10}$ & & & 0.815 & -0.315 & 0.211 & -0.081 & -0.002 & 1.067 & 0.096 & 0.053 & 0.002 \\
\hline$b_{11}$ & & & & 1.187 & -0.428 & 0.079 & -0.004 & -0.763 & -0.205 & -0.028 & 0.012 \\
\hline$b_{12}$ & & & & & 1.346 & -0.092 & -0.006 & -0.553 & 0.494 & -0.086 & -0.023 \\
\hline$b_{13}$ & & & & & & 0.931 & -0.944 & -0.004 & 0.074 & 0.294 & 0.031 \\
\hline$b_{14}$ & & & & & & & 1.944 & 0.644 & -0.199 & -0.135 & -0.013 \\
\hline$b_{15}$ & & & & & & & & 0.303 & 0.441 & -0.188 & -0.012 \\
\hline$b_{16}$ & & & & & & & & & 0.351 & 0.267 & 0.023 \\
\hline$b_{17}$ & & & & & & & & & & 0.981 & -0.921 \\
\hline$b_{18}$ & & & & & & & & & & & 1.912 \\
\hline$s$ & 44.053 & 28.864 & 19.316 & 14.350 & 11.790 & 19.647 & 6.139 & 30.922 & 18.581 & 14.395 & 6.182 \\
\hline$R^{2}$ & $96.11 \%$ & $98.04 \%$ & $99.07 \%$ & $99.50 \%$ & $99.67 \%$ & $98.91 \%$ & $99.87 \%$ & $96.48 \%$ & $98.60 \%$ & $98.23 \%$ & $99.86 \%$ \\
\hline$R_{\text {adj }}^{2}$ & $96.10 \%$ & $98.03 \%$ & $99.06 \%$ & $99.49 \%$ & $99.67 \%$ & $98.90 \%$ & $99.87 \%$ & $96.46 \%$ & $98.59 \%$ & $98.21 \%$ & $99.86 \%$ \\
\hline
\end{tabular}


Tests of the null hypothesis $\beta_{0}=\beta_{1}=\beta_{2}=\cdots=\beta_{k}=0$ at the selected level of significance 0.05 realized by Analysis of Variance for Significance of Regression in Multiple Regression, we concluded for all proposed regression models by rejecting this hypothesis and not rejecting the alternative hypothesis, $\mathrm{H}_{1}$ : Not all the $\beta_{i}, i=1,2, \cdots, k$ are zero, and thus confirming the existence of a multiple linear relationship between the independent variable and the dependent variables.

Table 4 shows that the influence of individual independent variables included in the regression models for calculating channel temperatures is not unambiguous but varies in terms of force (i.e., size of the coefficient) and terms of type (i.e., direct/indirect dependence). The last three lines of Table 4 contain selected results of correlation analysis, namely the standard error of estimate- $s$, the multiple coefficient of determination $-R^{2}$ and the adjusted multiple coefficient of determination $-R_{a d j}^{2}$.

The standard error of estimate- $s$ for individual models ranges from 6.1390 to 44.0534 , which is an acceptable result due to the size of the measured temperatures used (i.e., maximal is circa $1200^{\circ} \mathrm{C}$ ). Values of $R^{2}$ and $R_{a d j}^{2}$, ranging from $96.11 \%$ (i.e., for $T_{3}$ ) to $99.87 \%$ (i.e., for $T_{9}$ ), clearly show that each of the proposed regression models represents more than $96 \%$ of the variability of the dependent variable (i.e., channel temperature). Thus, it can be stated that the proposed regression models are suitable for use. The behavior of measured $T_{j}$ and modelled $T_{j}^{\text {mod }}$ temperature (i.e., for temperatures $T_{3}$ and $T_{9}$ ) is shown in Figure 10. The difference between the calculated values $R^{2}$ and $R_{a d j}^{2}$ is minimal due to the large number of data (i.e., $n=2846$ ), and therefore only the value $R_{a d j}^{2}$ is shown in the following tables.

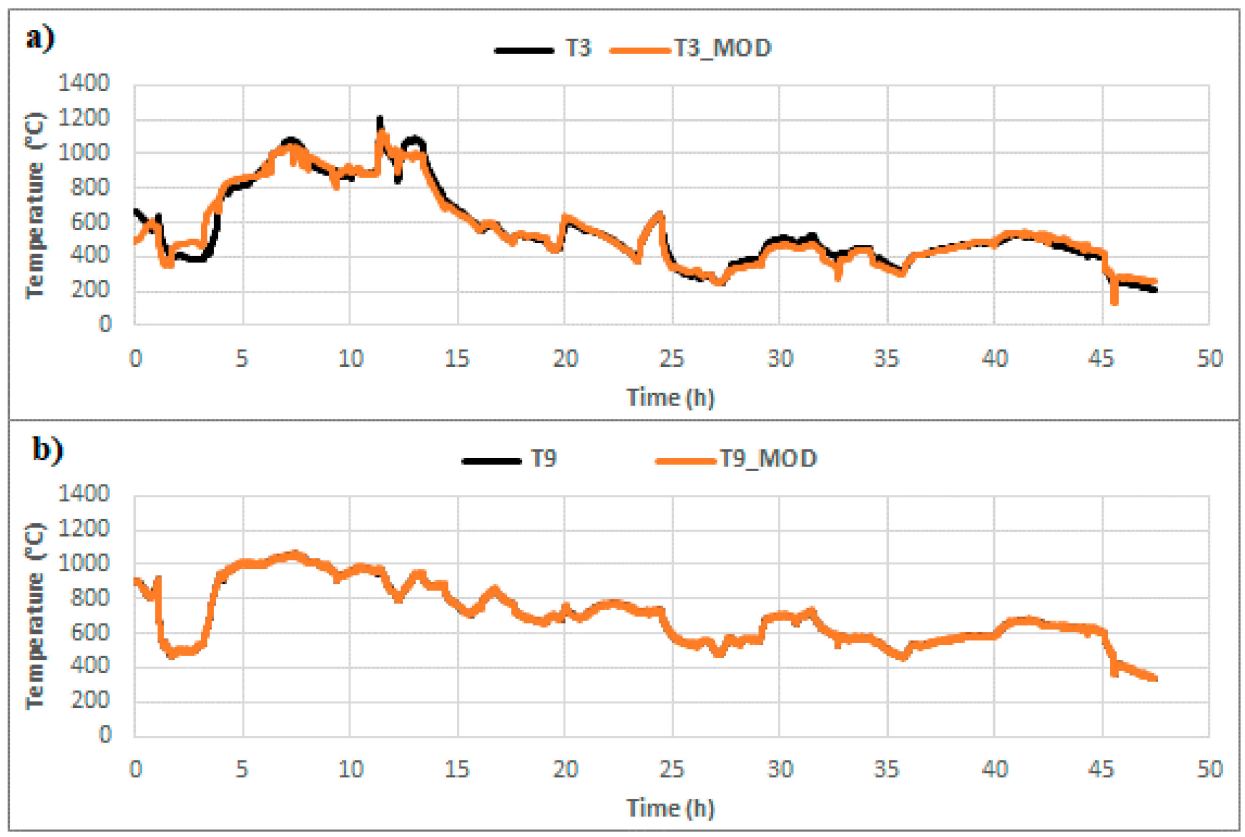

Figure 10. The measured (T) and modelled (T_MOD) temperature behavior, (a) temperature $T_{3}$, (b) temperature $T_{9}$ (Source: own elaboration).

In the next phase, we focused on solving temperatures in coal, i.e., temperatures $T_{17}$ and $T_{18}$. The proposed regression model included channel temperatures $T_{1}$ to $T_{7}$, i.e., temperatures located from the ignition place of the coal seam to the cross-section of the generator where the temperatures $T_{17}$ and $T_{18}$ were measured. The results of the correlation analysis (i.e., values $R^{2}$ and $R_{a d j}^{2}$ ) showed that temperatures measured in coal (i.e., temperatures $T_{16}$ and $T_{19}$ ) located in the same section as modeled temperatures are insignificant for the proposal of the model, and due to this reason were excluded from the 
models. The mathematical form of the proposed regression models for temperatures $T_{17}$ and $T_{18}$ can be written in general form, as follows:

$$
T_{j}^{\text {mod }}=b_{0}+\sum_{i=1}^{13} b_{i} \cdot x_{i}
$$

where: $T_{j}^{\text {mod }}$ are modelled temperatures for $j=17,18\left({ }^{\circ} \mathrm{C}\right) ; x_{1}$ is frequency $(\mathrm{Hz}) ; x_{2}$ is airflow $\left(\mathrm{m}^{3} \cdot \mathrm{h}^{-1}\right) ; x_{3}$ is oxygen $\left(\mathrm{m}^{3} \cdot \mathrm{h}^{-1}\right) ; x_{4}$ is calorific value $\left(\mathrm{MJ} . \mathrm{m}^{-3}\right) ; x_{5}$ is temperature $T_{1}\left({ }^{\circ} \mathrm{C}\right) ; x_{6}$ is temperature $T_{14}\left({ }^{\circ} \mathrm{C}\right) ; x_{7}$ is temperature $T_{15}\left({ }^{\circ} \mathrm{C}\right) ; x_{i}$ is temperature $T_{i-6}$ for $i=8,9, \cdots, 13\left({ }^{\circ} \mathrm{C}\right)$.

The calculated coefficients for individual models are shown in Table 5. The table shows that the temperature $T_{7}$ has the most significant influence on the modeled temperatures $T_{17}^{\text {mod }}$ (see Figure 11a) and $T_{18}^{\text {mod }}$ (see Figure $11 \mathrm{~b}$ ) of all considered measured temperatures (i.e., independent variables). The calorific value and airflow have a more significant effect on the modelled temperature $T_{18}^{m o d}$, which can be caused by the non-uniform gasifying coal along the right and left sides of the gasification channel.

Table 5. Coefficients of regression models for coal temperatures and values of multiple coefficient of determination and standard error of the estimate (Source: own elaboration).

\begin{tabular}{lccc}
\hline \multicolumn{2}{c}{ Coefficients } & $\boldsymbol{T}_{17}^{\text {mod }}$ & $\mathbf{T}_{18}^{\text {mod }}$ \\
\hline$b_{0}$ & 233.232 & 373.710 \\
$b_{1}$ & 1.119 & -0.343 \\
$b_{2}$ & -1.952 & -9.548 \\
$b_{3}$ & 5.449 & 1.597 \\
$b_{4}$ & -7.515 & -20.216 \\
$b_{5}$ & -0.957 & -0.245 \\
$b_{6}$ & 0.467 & -0.283 \\
$b_{7}$ & 0.098 & -0.038 \\
$b_{8}$ & 0.035 & 0.301 \\
$b_{9}$ & 0.649 & -0.091 \\
$b_{10}$ & 0.750 & -0.345 \\
$b_{11}$ & 0.155 & 3.187 \\
$b_{12}$ & 0.539 & 1.082 \\
$b_{13}$ & -1.286 & -3.587 \\
\hline$s$ & 66.82 & 115.56 \\
$R^{2}$ & $86.00 \%$ & $62.17 \%$ \\
$R_{a d j}^{2}$ & $85.94 \%$ & $61.98 \%$ \\
\hline
\end{tabular}

Table 5 shows that the values of the standard error of estimate- $s$ are higher (i.e., 66.82 and 115.56), and at the same time, the values $R^{2}$ (i.e., 86.00 and $62.17 \%$ ) and $R_{\text {adj }}^{2}$ (i.e., 62.17 and $61.98 \%$ ) are lower than at the modeled channel temperatures. This result indicates a worse prediction of coal temperatures by proposed regression models. A significant difference can be seen between correlation characteristics for temperature $T_{17}$ and $T_{18}$, which also supports the previous conclusion about the non-uniform gasifying coal along the sides of the gasification channel, i.e., the gasification process was faster on the temperature $T_{17}$ side. The difference in the velocity of gasifying coal was circa $6 \mathrm{~h}$. The temperature of $600{ }^{\circ} \mathrm{C}$ was reached on the left side of the gasification channel approximately at the 5 th hour, while on the right side at the 11 th hour. The difference of the burning velocities can be caused by uniform leakage of gasification agent through the upper edge of the ex situ reactor or by the fall of the overburden layers into the space of the formed cavity. 


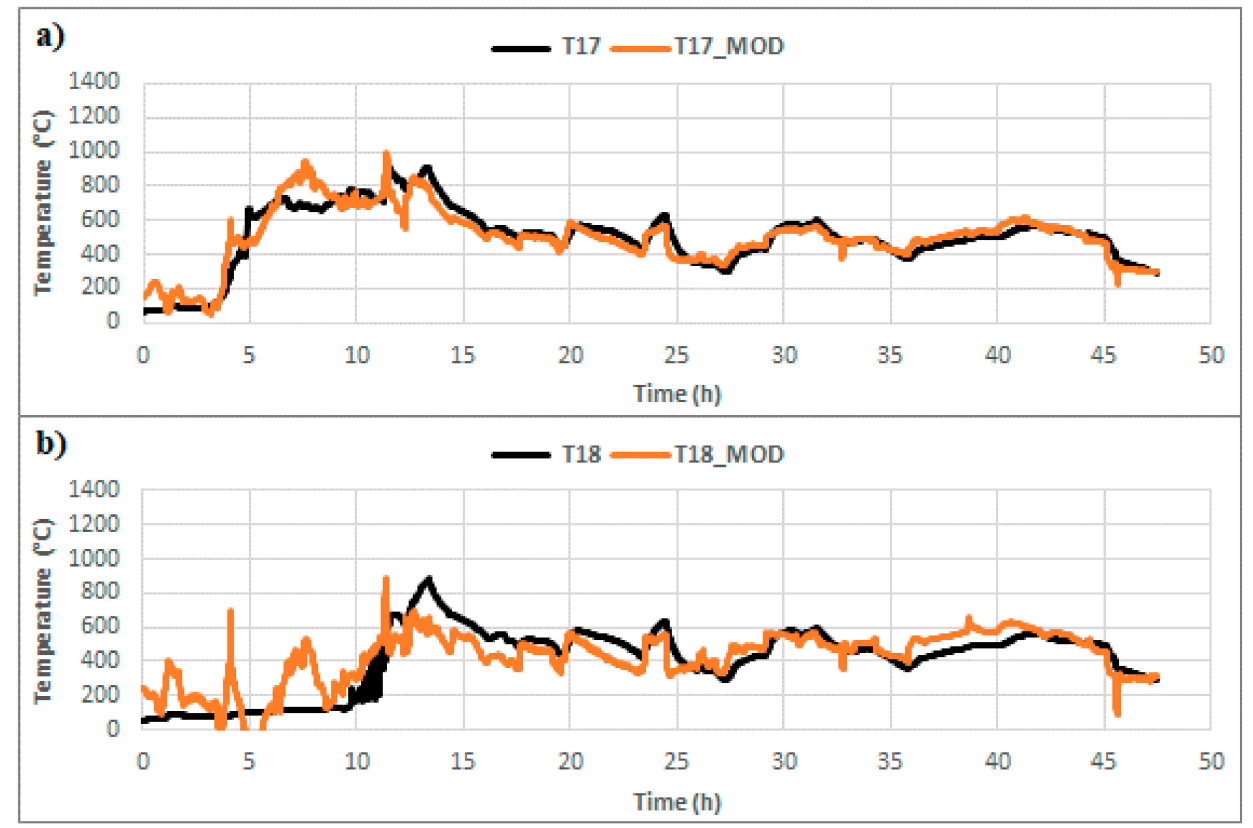

Figure 11. The measured (T) and modelled (T_MOD) temperature behavior, (a) temperature $T_{17}$, (b) temperature $T_{18}$ (Source: own elaboration).

\subsection{Coefficients Application of Multiple Linear Regression Models on Data from the Second Experiment}

Multiple linear regression models proposed for the data from the first experiment were verified on the data from the second experiment. This experiment differed in the amount of gasified coal (see Section 2.2) and the gasification time. Proposed regression models were applied only to the measured data from the second experiment in the first phase of verification. Modeled temperature values from the proposed regression models were used to calculate temperatures depending on their values during the second verification phase. For example, the modeled temperature $T_{3}$ (i.e., $T_{3}^{m o d}$ ) was used in the temperature calculation $T_{4}$, and then the modeled temperature values $T_{3}$ (i.e., $T_{13}^{\text {mod }}$ ) and $T_{4}$ (i.e., $T_{4}^{\text {mod }}$ ) were used to calculate the temperature $T_{5}$, etc. The goal of this phase was to verify whether it is possible to use only measured temperatures at the input to the ex situ reactor (i.e., $T_{1}$, $T_{2}, T_{14}$, and $T_{15}$ ) to calculate temperatures in the gasified coal seam model (i.e., from $T_{3}$ to $T_{13}$, and $T_{17}$ and $T_{18}$ ). It was assumed that in a real gasified coal seam are not suitable conditions for measuring temperatures along the length of this coal seam.

The graph shown in Figure 12 contains selected results of correlation analysis for both phases, i.e., $R_{a d j 1}^{2}$ values for the first phase and $R_{a d j 2}^{2}$ values for the second phase. Assuming that in the best case, the modeled values exactly match the observed values, $R^{2}=1$ or $100 \%$, in the opposite case, i.e., if $R^{2}=0$, modeled values do not correspond to the measured values at all. The deviation between the measured and modeled values in some cases was so large that $R_{a d j}^{2}$ values were not within the specified range because coefficients calculated from the measured values of the 1st experiment were applied to the values of the 2 nd experiment. Therefore, these values were replaced by $0 \%$ in the graph. 


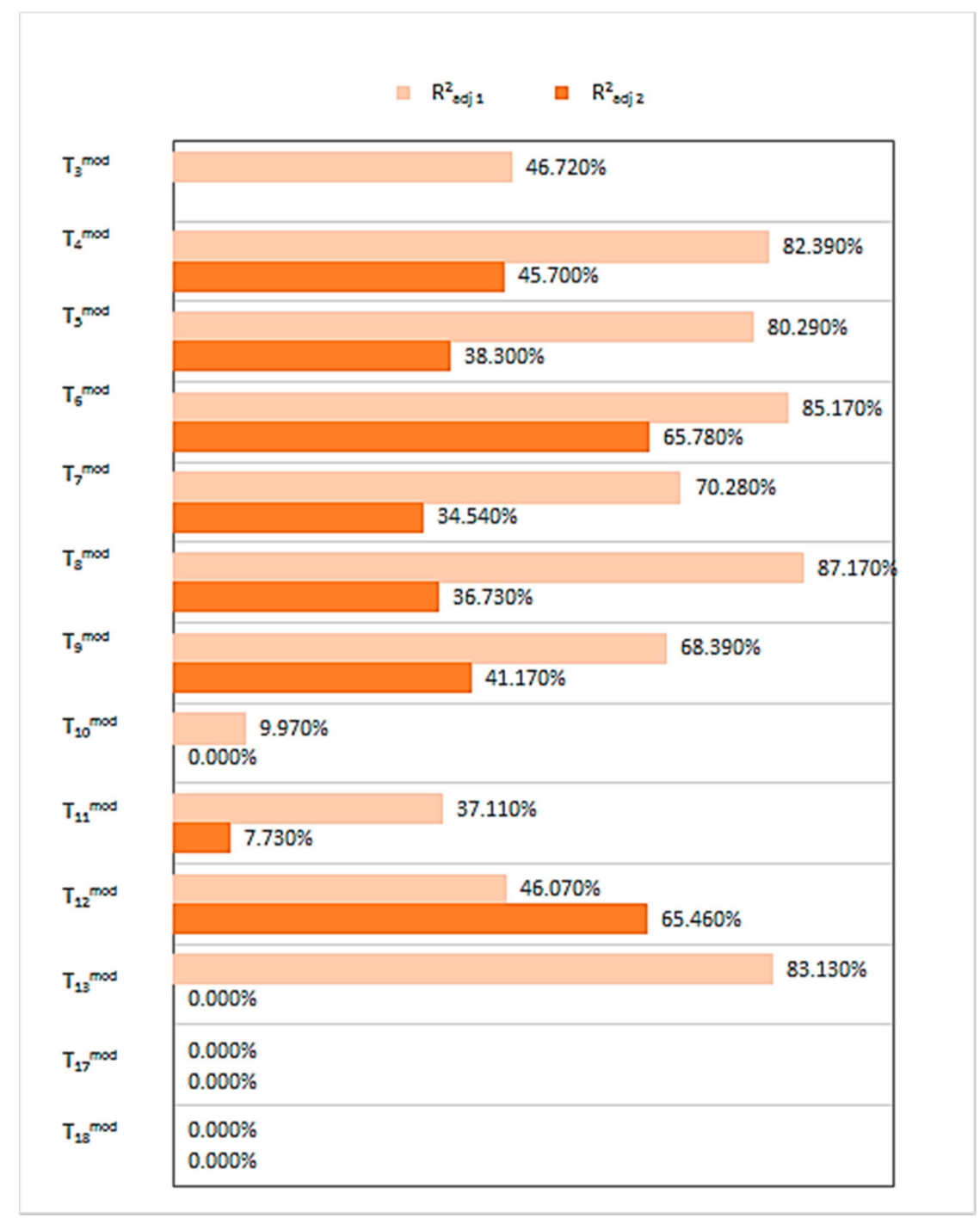

Figure 12. Values $R_{a d j}^{2}$ of proposed regression models for the first phase- $R_{a d j 1}^{2}$ and the second phase $-R_{a d j 2}^{2}$ (Source: own elaboration).

The values of the multiple coefficient of determination for channel temperatures at the first phase are significantly lower than their values in the first experiment and differ significantly from each other. The maximum value of the multiple coefficient of determination was reached at the measured temperature $T_{8}$ (see Figure 13a). Thus, it was possible to represent $87.17 \%$ of the variance of the original variable by its regression model. The smallest value of the multiple coefficient of determination was reached for the measured temperature $T_{10}$ (see Figure $13 \mathrm{~b}$ ) when it was possible to represent only $9.97 \%$ of the variance of the original variable.

It can be observed in Figure 14a,b differences in the progress of the burning coal on the right and left sides of the ex situ. At the same time, it is possible to see that twice the volume of coal in the ex situ reactor caused the application of the proposed models from the first experiment for coal temperatures $T_{17}$ and $T_{18}$ shows more significant deviations than for channel temperatures. The regression model of temperature $T_{17}$ in the second half-time of the experiment shows significantly lower deviations to the measured values than in its first half-time (see Figure 14a). 


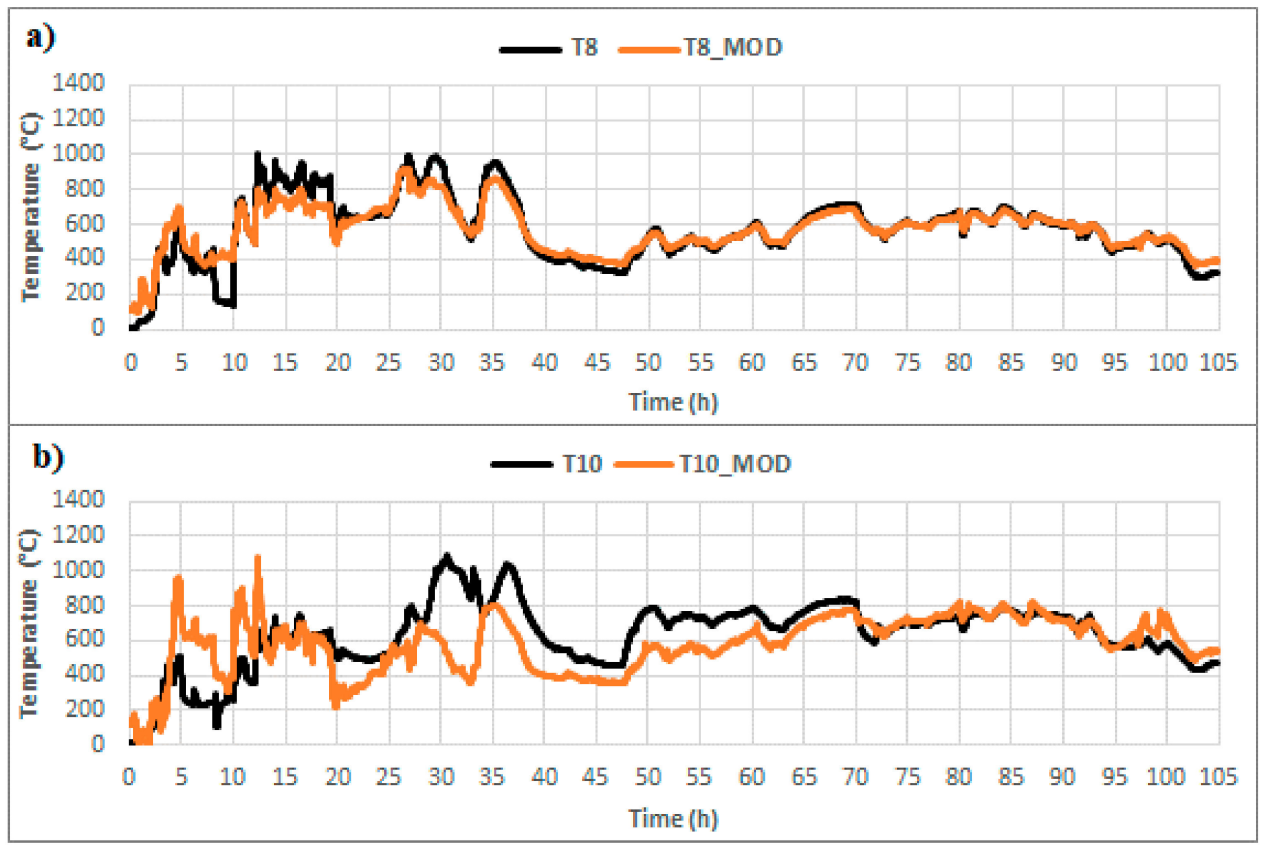

Figure 13. The measured $(\mathrm{T})$ and modeled (T_MOD) temperature behavior, $(\mathbf{a})$ temperature $T_{8}$, (b) temperature $T_{10}$ (Source: own elaboration).

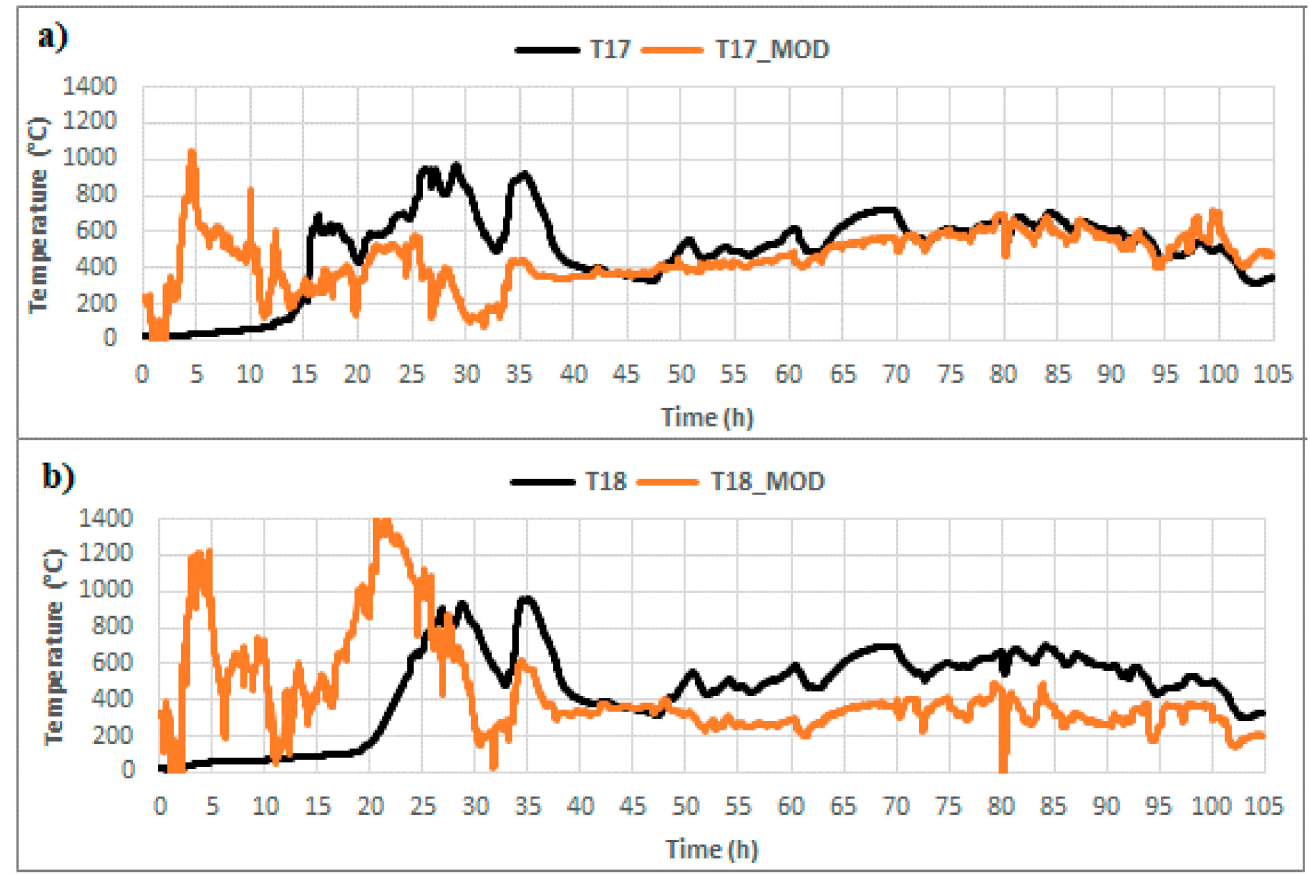

Figure 14. The measured $(\mathrm{T})$ and modeled (T_MOD) temperature behavior in the first phase verification, (a) temperature $T_{17},(\mathbf{b})$ temperature $T_{18}$ (Source: own elaboration).

The application of regression models using the modeled temperatures in the second phase verification showed that multiple coefficients of determination are even lower than for the first phase. The maximum value of $65.78 \%$ was obtained for temperature $T_{6}$ (see Figure 15a), and the minimum value of $7.73 \%$ was obtained for temperature $T_{11}$ (see Figure $15 \mathrm{~b}$ ). The zero values $R_{a d j}^{2}$ for temperatures $T_{10}, T_{13}, T_{17}$, and $T_{18}$ indicate a low agreement of measured and model values, i.e., the unsuitability of using the proposed regression models obtained from the first experiment for modeling temperatures in the second experiment. The graphs of temperatures $T_{17}$ (see Figure 16a) and for $T_{18}$ (see 
Figure $16 b)$ are shown to a better visual representation.

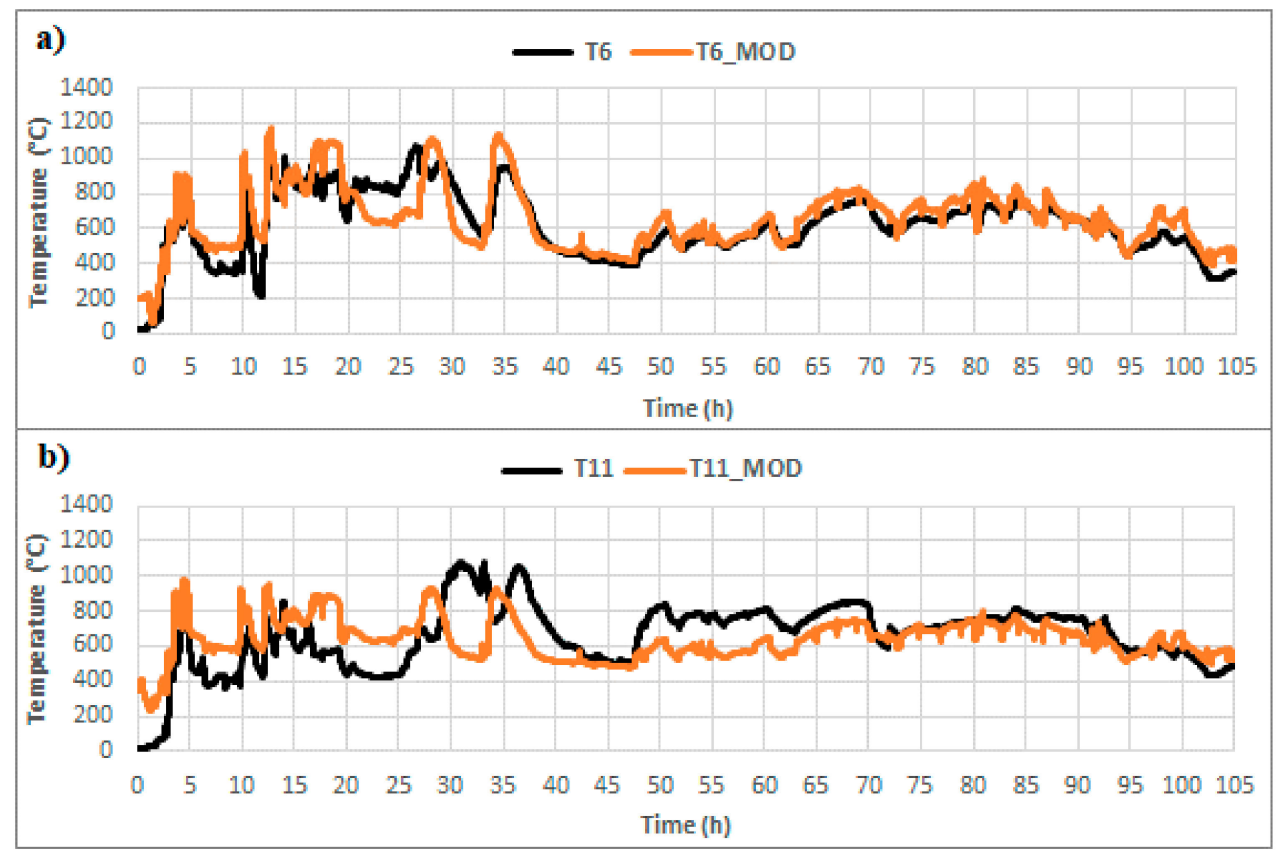

Figure 15. The measured (T) and modeled (T_MOD) temperature behavior, $(\mathbf{a})$ temperature $T_{16}$, (b) temperature $T_{11}$ (Source: own elaboration).

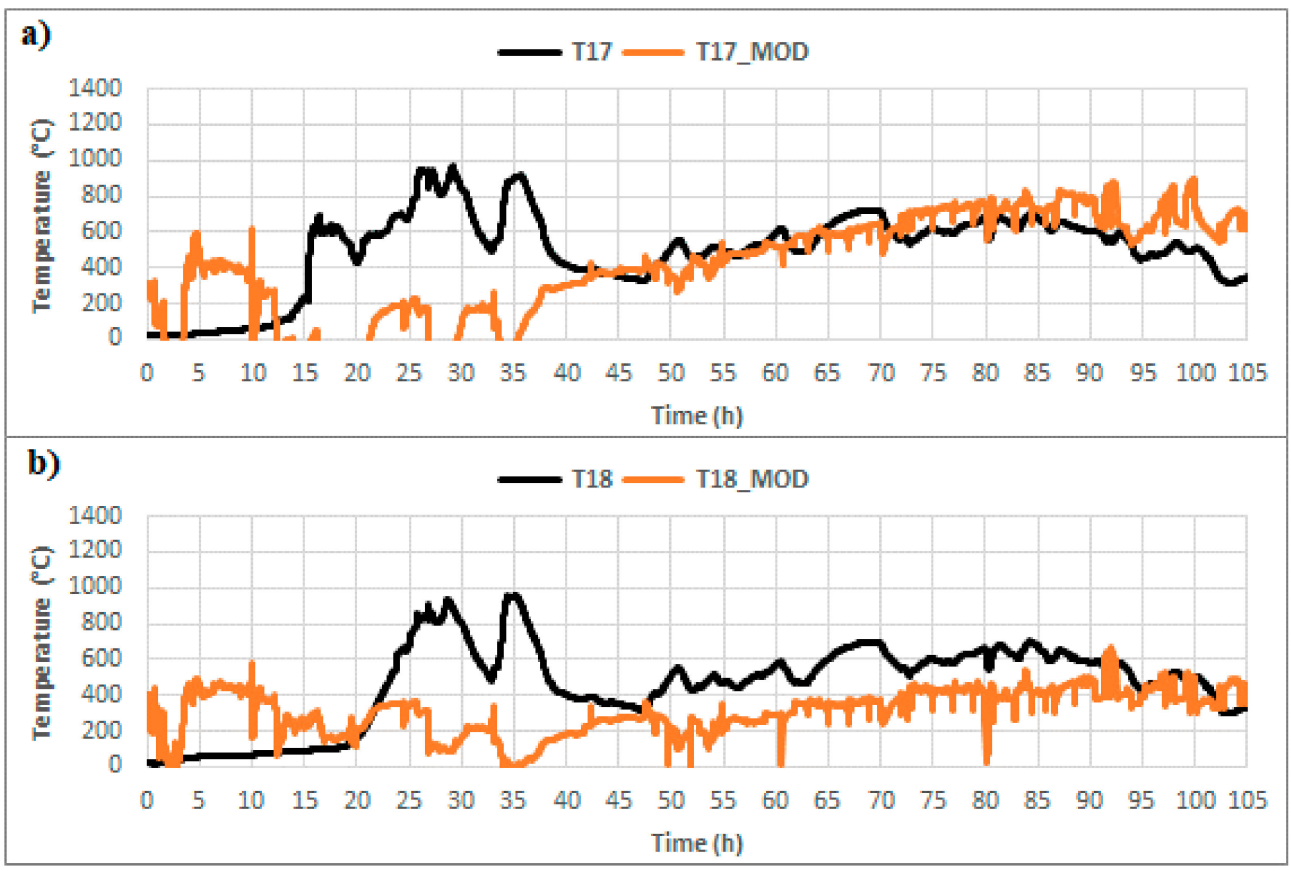

Figure 16. The measured (T) and modeled (T_MOD) temperature behavior in the second phase verification, (a) temperature $T_{17},(\mathbf{b})$ temperature $T_{18}$ (Source: own elaboration).

The conditions of the second experiment realization were different from the first experiment's conditions due to the volume of gasified coal and the insulating materials used. Therefore, it was difficult to apply the proposed regression models based on data from the first experiment for data from the second experiment. The use of modeled temperatures in the second phase verification instead of those measured caused the deviations transfer of dependent variable values to the calculations of other temperatures. For this reason, we 
focused on creating regression models with a lesser number of independent variables in the next solution.

\subsection{The Proposal of a Modified Multiple Linear Regression Model for the Channel's and Coal's Temperatures}

We tested several multiple linear regression models calculated based on the measured values from the first experiment to optimize the number of independent variables. These tests have differed from each other in the number of independent variables involved in regression models. The most suitable type of regression model for modeling channel temperatures $T_{3}$ to $T_{13}$ in terms of the minimum value of the multiple coefficient of determination proved to be a model including only two independent variables, namely calorific value and temperature (e.g., $T_{2}$ for $T_{3}$ calculation, $T_{3}$ for $T_{4}$ calculation, etc.). The proposed type of regression model can be written in the following form:

$$
T_{j}^{m o d}=b_{0}+b_{1} \cdot x_{1}+b_{2} \cdot x_{2}
$$

where: $T_{j}^{\text {mod }}$ are modeled temperatures for $j=3,4, \cdots, 13\left({ }^{\circ} \mathrm{C}\right) ; x_{1}$ is calorific value $\left(\mathrm{MJ} . \mathrm{m}^{-3}\right) ; x_{2}$ is temperature $T_{j-1}\left({ }^{\circ} \mathrm{C}\right)$.

The calculated coefficients for individual regression models of modelled channel temperatures and selected correlation characteristics (i.e., s and $R_{a d j}^{2}$ ) are shown in Table 6. The effect of calorific value expressed by the individual calculated coefficients $b_{1}$ is predominantly indirect because the calculated coefficients have mostly negative signs. The effect of temperature is always direct, which can be seen in the positive values of the calculated coefficients $b_{2}$.

Table 6. Coefficients of modified regression models for channel temperatures and values of a multiple coefficient of determination and a standard error of the estimate (Source: own elaboration).

\begin{tabular}{lccccc}
\hline Predicted Temperature & $\boldsymbol{b}_{0}$ & $\boldsymbol{b}_{1}$ & $\boldsymbol{b}_{2}$ & $\boldsymbol{s}$ & $\boldsymbol{R}_{\boldsymbol{a d j}}^{2}$ \\
\hline$T_{3}^{\text {mod }}$ & 106.564 & -2.890 & 0.855 & 64.625 & $91.60 \%$ \\
$T_{4}^{\text {mod }}$ & 107.575 & -4.334 & 0.918 & 34.127 & $97.20 \%$ \\
$T_{5}^{\text {mod }}$ & 46.542 & 0.153 & 0.962 & 24.200 & $98.50 \%$ \\
$T_{6}^{\text {mod }}$ & 1.378 & 1.952 & 0.998 & 28.016 & $98.10 \%$ \\
$T_{7}^{\text {mod }}$ & -3.909 & 0.799 & 1.011 & 16.123 & $99.40 \%$ \\
$T_{8}^{\text {mod }}$ & 105.407 & -3.932 & 0.912 & 27.346 & $97.90 \%$ \\
$T_{9}^{\text {mod }}$ & 70.103 & -5.691 & 0.928 & 29.542 & $97.10 \%$ \\
$T_{10}^{\text {mod }}$ & 39.156 & -2.646 & 0.944 & 17.296 & $98.90 \%$ \\
$T_{11}^{\text {mod }}$ & 31.217 & -3.239 & 0.953 & 18.223 & $98.60 \%$ \\
$T_{12}^{\text {mod }}$ & 4.998 & -5.582 & 0.993 & 33.147 & $95.60 \%$ \\
$T_{13}^{\text {mod }}$ & -25.378 & -6.724 & 1.039 & 32.607 & $96.10 \%$ \\
\hline
\end{tabular}

Tests of the null hypothesis $\beta_{0}=\beta_{1}=\beta_{2}=\cdots=\beta_{k}=0$ at the selected level of significance 0.05 realized by Analysis of Variance for Significance of Regression in Multiple Regression, we concluded for all proposed regression models by rejecting this hypothesis and not rejecting the alternative hypothesis, $\mathrm{H}_{1}$ : Not all the $\beta_{i}, i=1,2, \cdots, k$ are zero, and thus confirming the existence of a multiple linear relationship between the independent variable and the dependent variables.

The standard error of estimate — $s$ for individual models ranges from 17.296 to 34.127, only for temperature $T_{3}$ is higher (i.e., 64.625). It is an acceptable result due to the size of the measured temperatures (i.e., maximal is circa $120{ }^{\circ} \mathrm{C}$ ). Values of $R_{a d j}^{2}$, ranging from $91.60 \%$ (i.e., for temperature $T_{3}$ ) to $99.40 \%$ (i.e., for temperature $T_{7}$ ), clearly show that each of the proposed regression models represents more than $91 \%$ of the variability of the dependent variable (i.e., channel temperature). Thus, it can be stated that the proposed regression models are suitable for use. The behavior of measured $T_{j}$ and modeled $T_{j}^{\text {mod }}$ temperature (i.e., for temperatures $T_{3}$ and $T_{7}$ ) is shown in Figure 17a,b. 

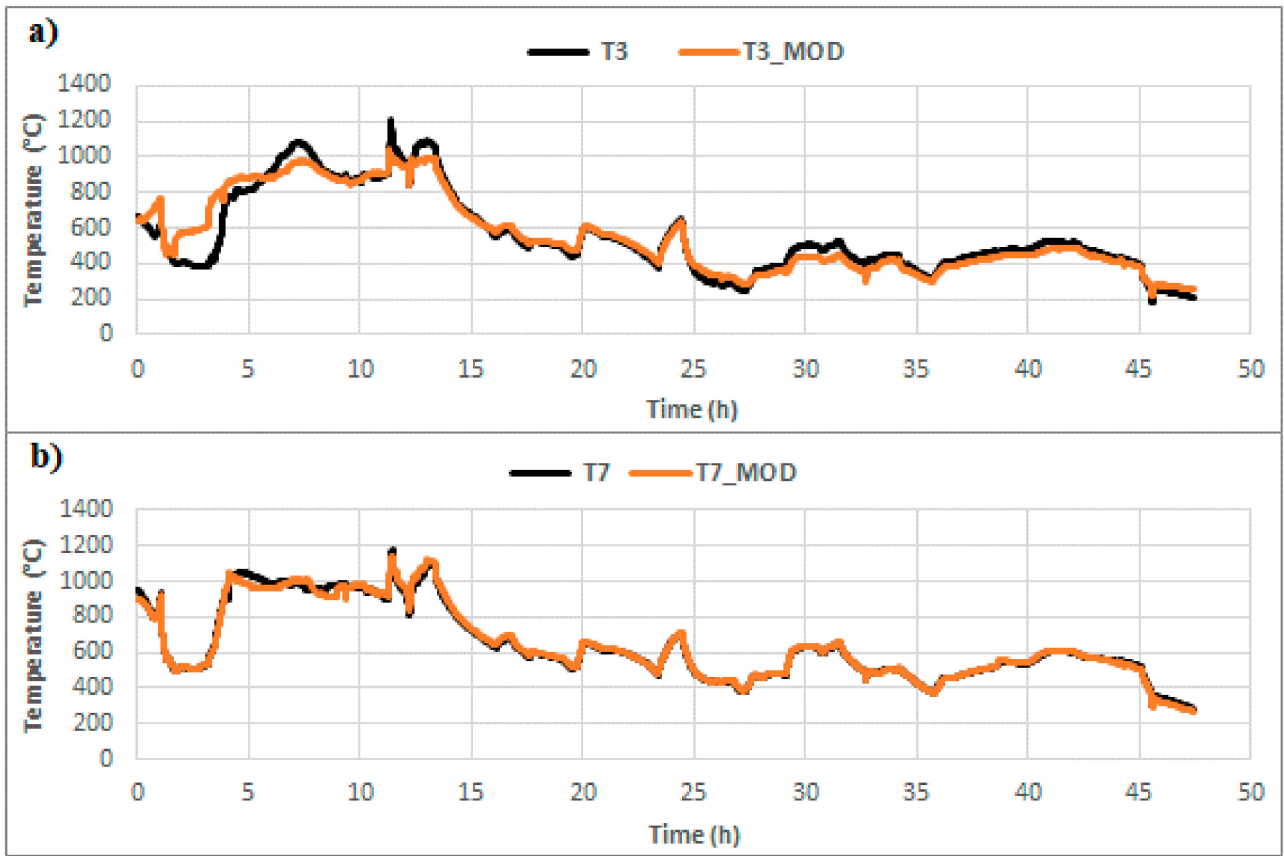

Figure 17. The measured $(\mathrm{T})$ and modeled (T_MOD) temperature behavior, (a) temperature $T_{3}$, (b) temperature $T_{7}$ (Source: own elaboration).

After analyzing several variants of the solution, a model for temperatures in coal (i.e., for temperatures $T_{17}$ and $T_{18}$ ) was proposed. This model includes four independent variables, i.e., calorific value, channel temperature $T_{7}$ and temperatures $T_{16}$ and $T_{19}$ measured in the insulation layer at the edges of the ex situ reactor. The solution was based on the assumption of measuring temperatures in the surrounding rocks of the gasified coal seam. The proposed model can be written in the following form:

$$
T_{j}^{\text {mod }}=b_{0}+b_{1} \cdot x_{1}+b_{2} \cdot x_{2}+b_{3} \cdot x_{3}+b_{4} \cdot x_{4}
$$

where: $T_{j}^{m o d}$ are modelled temperatures for $j=17,18\left({ }^{\circ} \mathrm{C}\right) ; x_{1}$ is calorific value $\left(\mathrm{MJ} . \mathrm{m}^{-3}\right)$; $x_{2}$ is temperature $T_{7}\left({ }^{\circ} \mathrm{C}\right) ; x_{3}$ is temperature $T_{16} ; x_{4}$ is temperature $T_{19}\left({ }^{\circ} \mathrm{C}\right)$.

The calculated coefficients for individual regression models of modeled coal temperatures and selected correlation characteristics (i.e., $s$ and $R_{a d j}^{2}$ ) are shown in Table 7. The modified regression model of temperature $T_{17}$ (see Figure 18a) worse represents measured temperature $T_{17}$ in the first $10 \mathrm{~h}$ of the experiment while compared to the regression model results shown in Figure 11a. This conclusion is also confirmed by the reduction of $R_{a d j}^{2}$ values from 85.94 to $71.48 \%$. The modified regression model of temperature $T_{18}$ (see Figure 18b) better represents measured temperature $T_{18}$ during the experiment than the regression model shown in Figure 11b. Proof that this is an increase in $R_{a d j}^{2}$ values from 61.98 to $95.65 \%$.

Table 7. Coefficients of modified regression models for coal temperatures and values of a multiple coefficient of determination and a standard error of the estimate (Source: own elaboration).

\begin{tabular}{lccccccc}
\hline Predicted Temperature & $\boldsymbol{b}_{0}$ & $\boldsymbol{b}_{1}$ & $\boldsymbol{b}_{2}$ & $\boldsymbol{b}_{3}$ & $\boldsymbol{b}_{4}$ & $\boldsymbol{s}$ & $\boldsymbol{R}_{\text {adj }}^{2}$ \\
\hline$T_{17}^{\text {mod }}$ & -87.233 & 0.110 & 0.543 & 0.414 & 0.156 & 95.179 & $71.48 \%$ \\
$T_{18}^{\text {mod }}$ & 9.627 & 12.987 & -0.031 & 0.466 & 0.533 & 39.866 & $95.65 \%$ \\
\hline
\end{tabular}




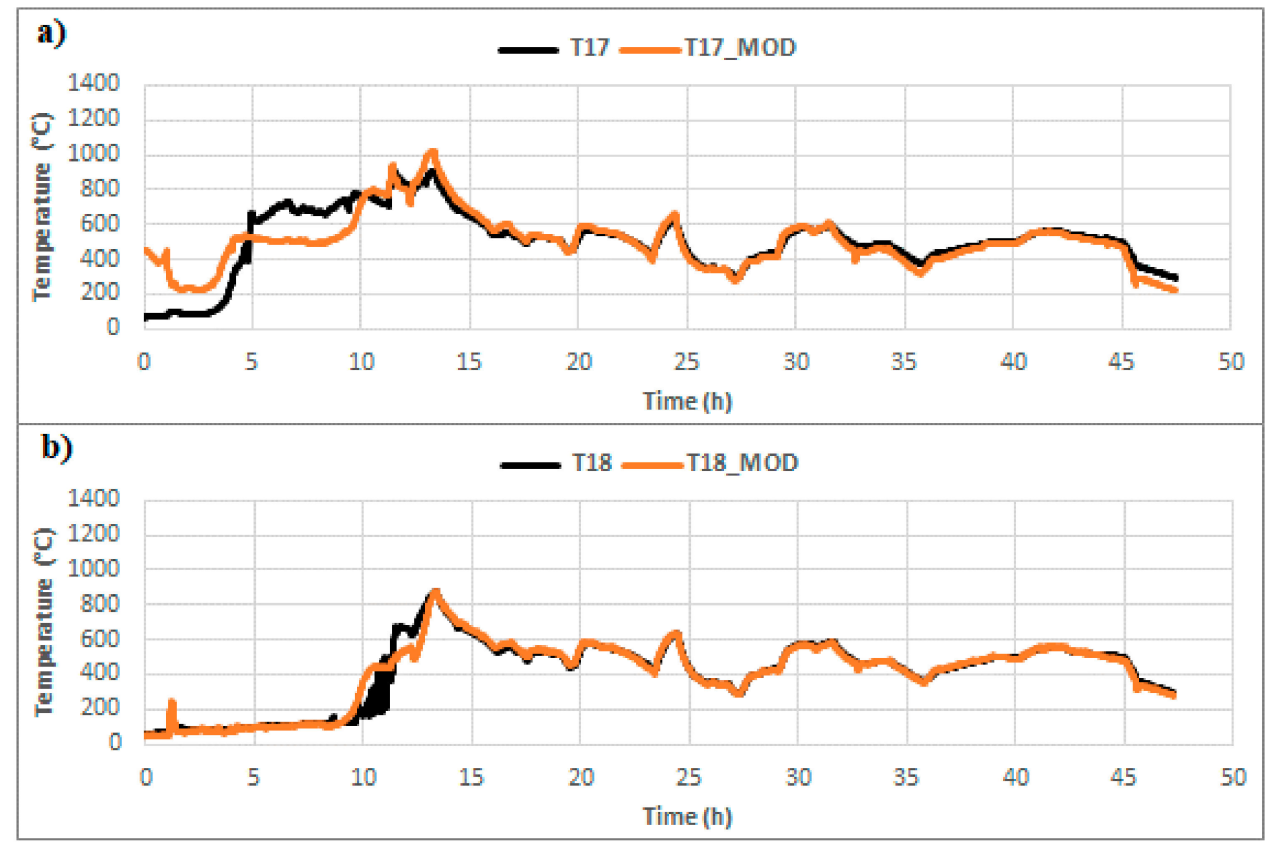

Figure 18. The measured $(\mathrm{T})$ and modeled (T_MOD) temperature behavior by using modified regression models, (a) temperature $T_{17},(\mathbf{b})$ temperature $T_{18}$ (Source: own elaboration).

4.4. Coefficients Application of Modified Multiple Linear Regression Models on Data from the Second Experiment

The modified multiple linear regression models proposed for the data from the first experiment were verified on the data from the second experiment similarly as in the case of the verification of regression models described in Section 4.2. Two phases were used in the verification, similar to the previous cases. At first, the calculations were performed only with the measured data and subsequently also with calculated. Selected results of the correlation analysis- $R_{a d j}^{2}$ values for all modeled temperatures are shown in Figure 19.

The first verification phase's multiple coefficient of determination values $R_{a d j 1}^{2}$ were in a range from $77.15 \%$ (i.e., temperature $T_{13}$ ) to $94.99 \%$ (i.e., temperature $T_{3}$ ) for channel temperatures calculated only from the measured temperatures. It is possible to observe a decreasing trend of these values towards the ex situ reactor output based on these values. The behavior of measured and modelled temperatures $T_{3}$ and $T_{13}$ is shown in Figure 20a,b.

It is visible a significant improvement in the representation of measured coal temperatures by modeled coal temperatures in compared temperature behaviors in Figure 21a,b with temperature behaviors in Figure 14a,b. This result is also confirmed by the achieved values $R_{a d j 1}^{2}$, i.e., $48.936 \%$ for temperature $T_{17}$ and $48.471 \%$ for temperature $T_{18}$ (see Figure 19).

The second verification phase's multiple coefficient of determination values $R_{a d j 2}^{2}$ were in a range from $8.54 \%$ (i.e., temperature $T_{9}$ ) to $83.08 \%$ (i.e., temperature $T_{4}$ ) for channel temperatures calculated from the modeled temperatures. It is possible to observe a decrease in these values towards the ex situ reactor output based on these values. This decrease is due to reducing the number of independent variables, i.e., by minimization of the transmitted calculation error. We can state that the applicability of the proposed models is sufficient for temperatures $T_{4}$ to $T_{6}$ by observing the values of $R_{a d j 2}^{2}$ for temperatures measured in the gasification channel. The behavior of measured and modeled temperatures $T_{4}$ and $T_{9}$ is shown in Figure 22a,b. 


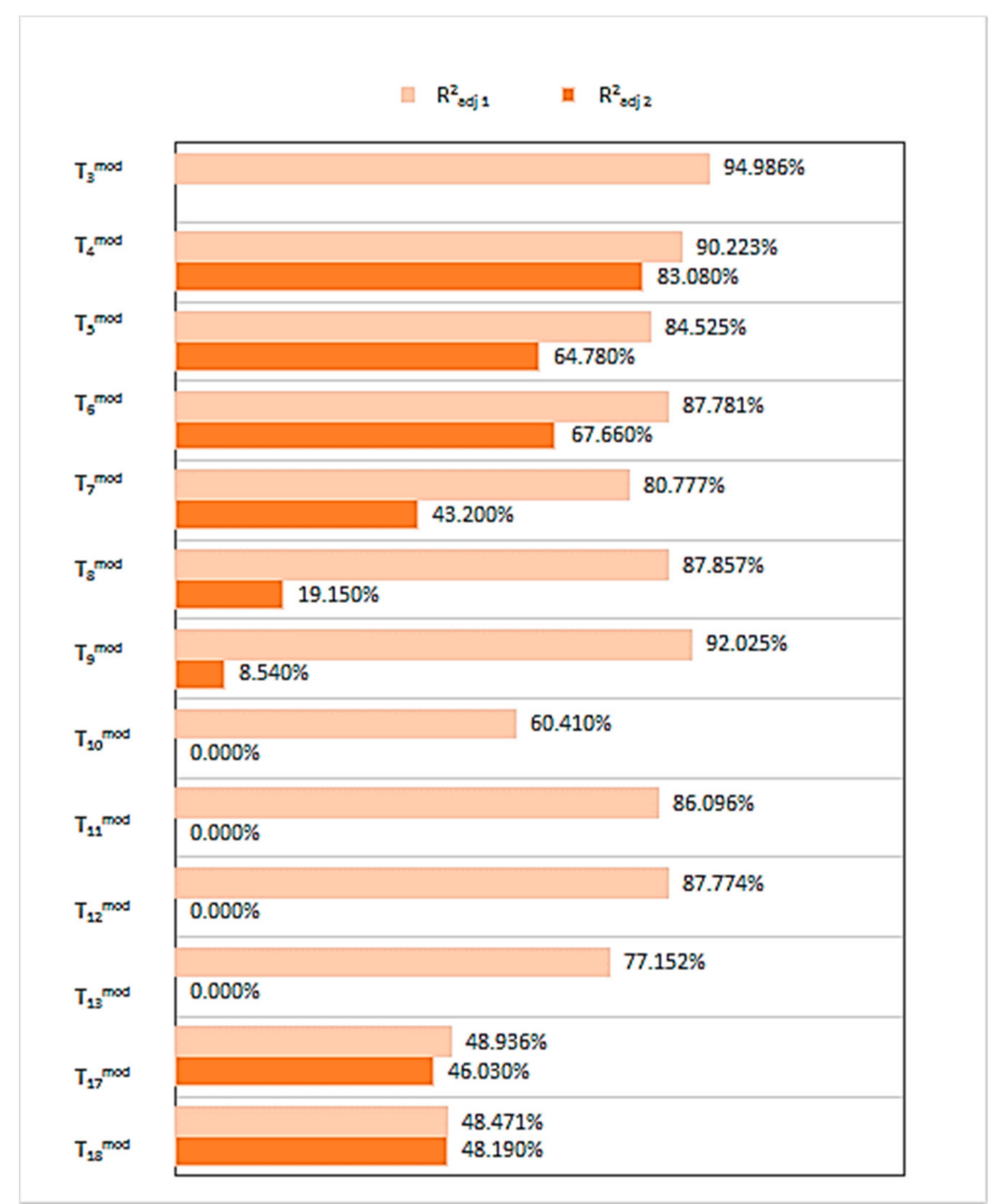

Figure 19. Values $R_{a d j}^{2}$ of modified regression models for the first phase- $R_{a d j 1}^{2}$ and the second phase $-R_{a d j 2}^{2}$ (Source: own elaboration).

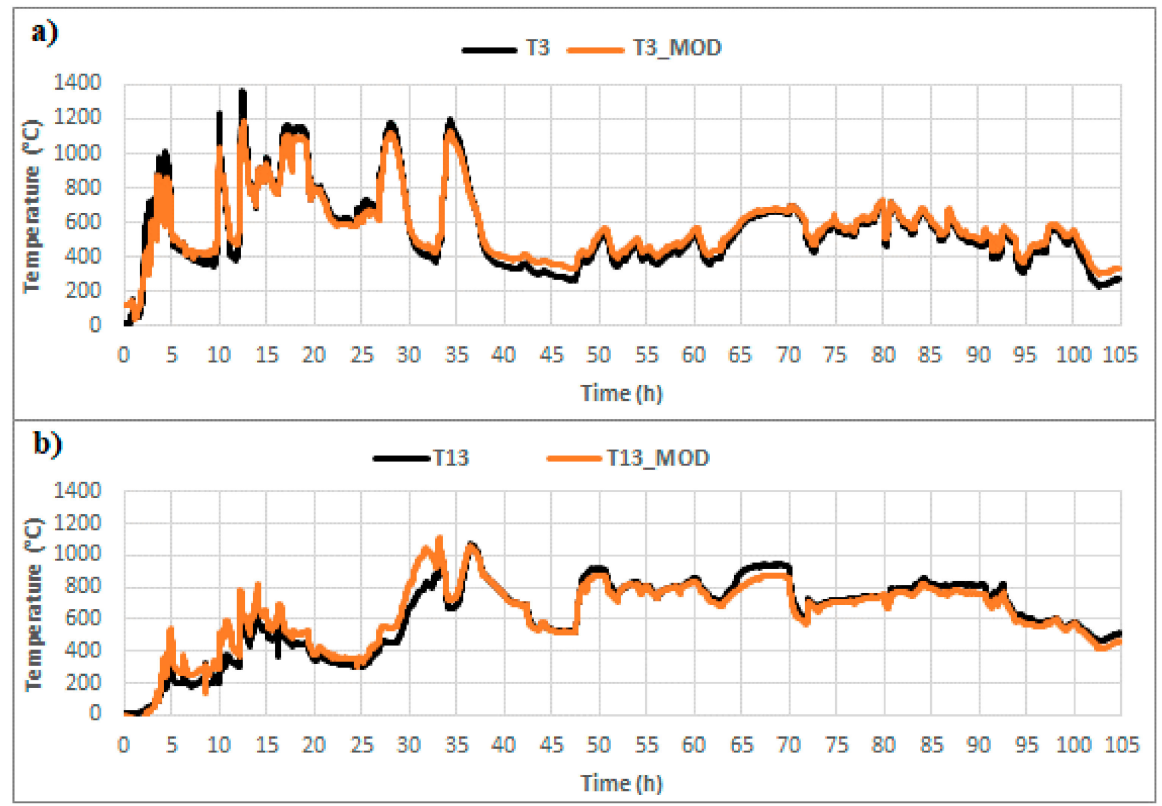

Figure 20. The measured $(\mathrm{T})$ and modeled $\left(\mathrm{T} \_\mathrm{MOD}\right)$ temperature behavior, $(\mathbf{a})$ temperature $T_{3},(\mathbf{b})$ temperature $T_{13}$ (Source: own elaboration). 


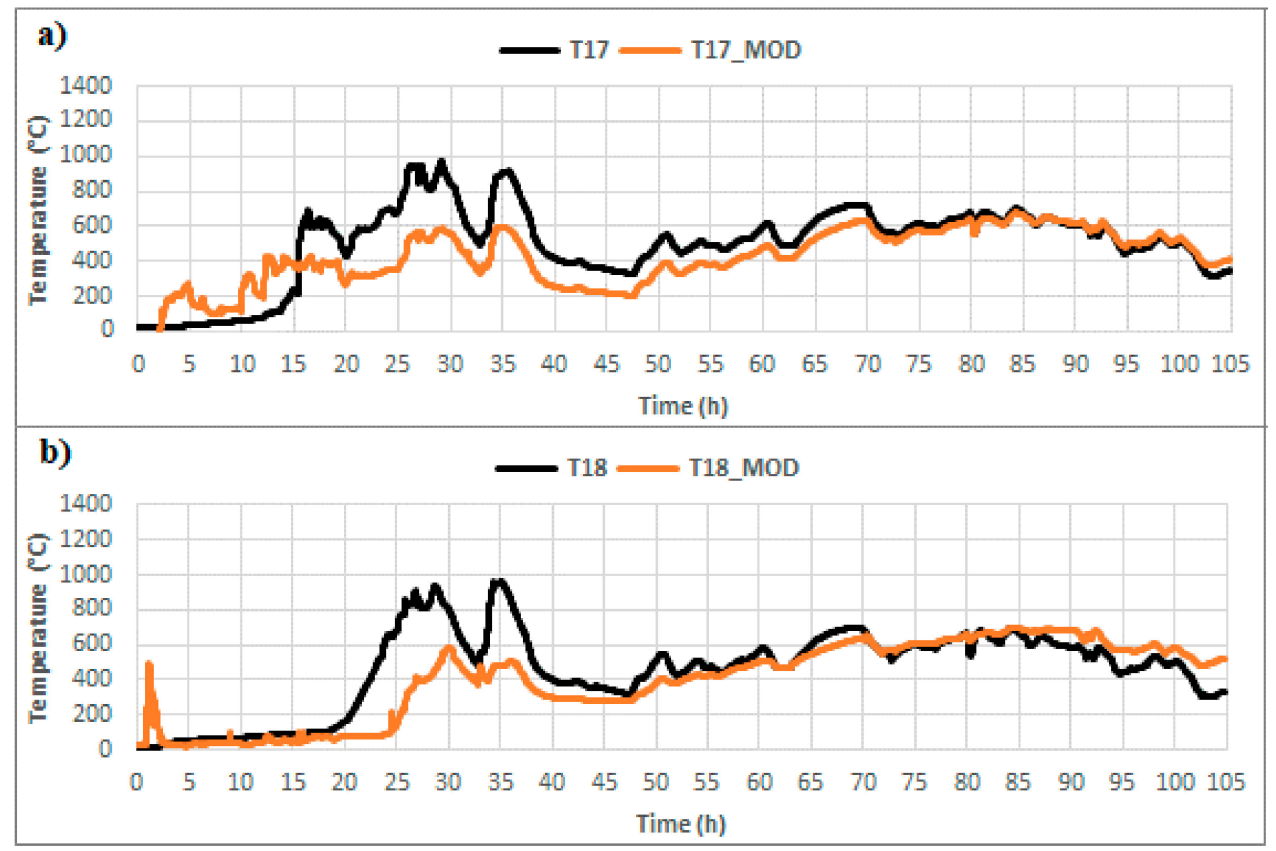

Figure 21. The measured $(\mathrm{T})$ and modeled (T_MOD) temperature behavior in the first phase verification by using modified regression models, (a) temperature $T_{17},(\mathbf{b})$ temperature $T_{18}$ (Source: own elaboration).

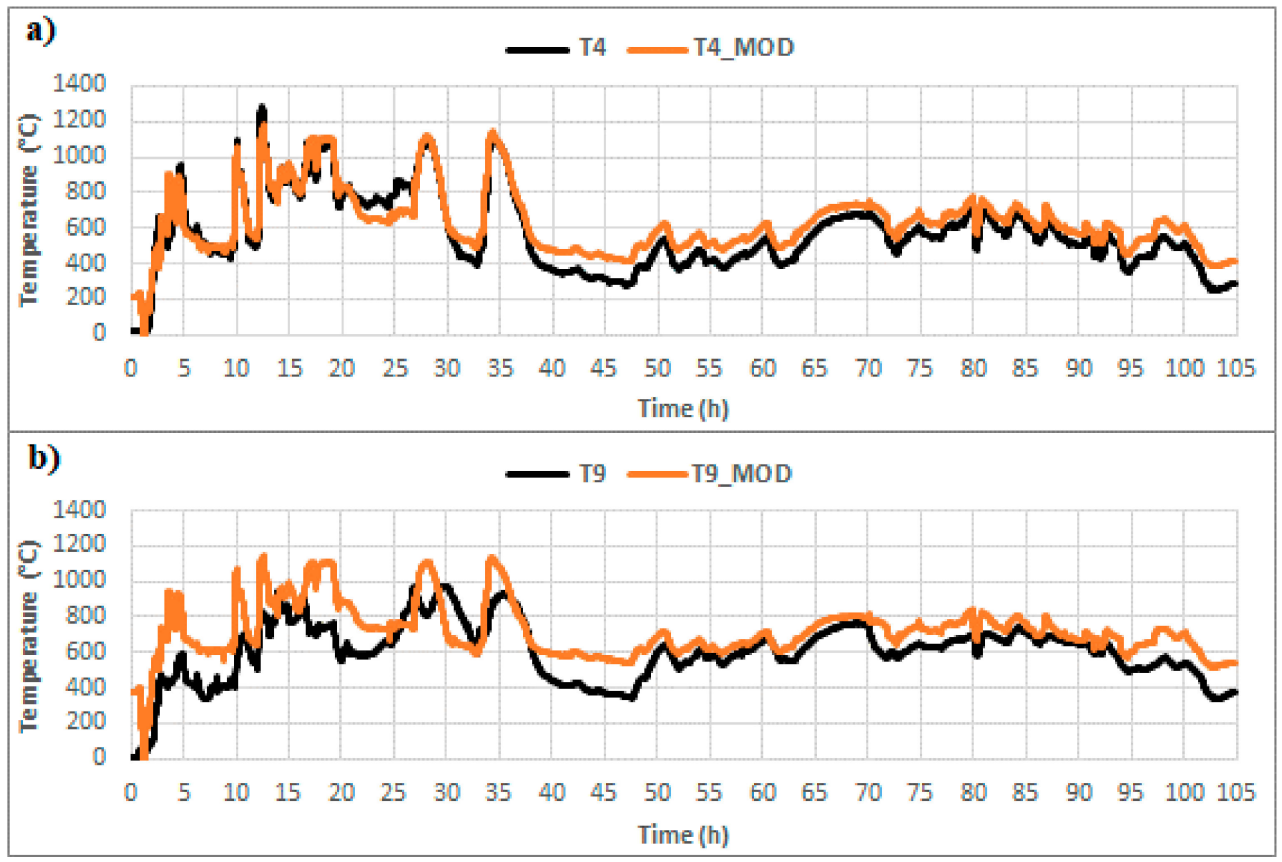

Figure 22. The measured (T) and modeled (T_MOD) temperature behavior, $(\mathbf{a})$ temperature $T_{4},(\mathbf{b})$ temperature $T_{9}$ (Source: own elaboration).

Results showed a significant improvement in the representation of measured values by modeled values at comparison modeled coal temperatures showed in Figure 23a,b to modeled coal temperatures showed in Figure 16a,b. It is confirmed by the achieved values $R_{a d j 2}^{2}=46.03 \%$ for temperature $T_{17}$ and $48.19 \%$ for temperature $T_{18}$. The achieved values of $R_{a d j}^{2}$ in the first and second phases have differed only minimally, i.e., the replacement measured values by calculated values did not reduce the expression quality of the dependent variable variance (i.e., temperature $T_{17}$ or $T_{18}$ ). Reach values $R_{a d j}^{2}$, around $50 \%$, are 
low in terms of the suitability of these models. We can say that the deviations between the measured and modelled values of the dependent variables $T_{17}$ and $T_{18}$ are significantly lower from the 45th hour of the experiment. Deviations of these temperatures in the first half of the experiment cause small values of $R_{a d j 2}^{2}$ (see Figure 23a,b). The similarity of temperature behaviors between Figures $21 \mathrm{~b}$ and $23 \mathrm{~b}$ is caused by lower value regression coefficient $b_{2}$ (i.e., -0.031 ). This coefficient lower value reduces the effect of the temperature $T_{7}$ (i.e., measured in the first phase verification and modelled in the second phase verification, at the temperature $T_{18}$ calculation) on the temperature $T_{18}$.

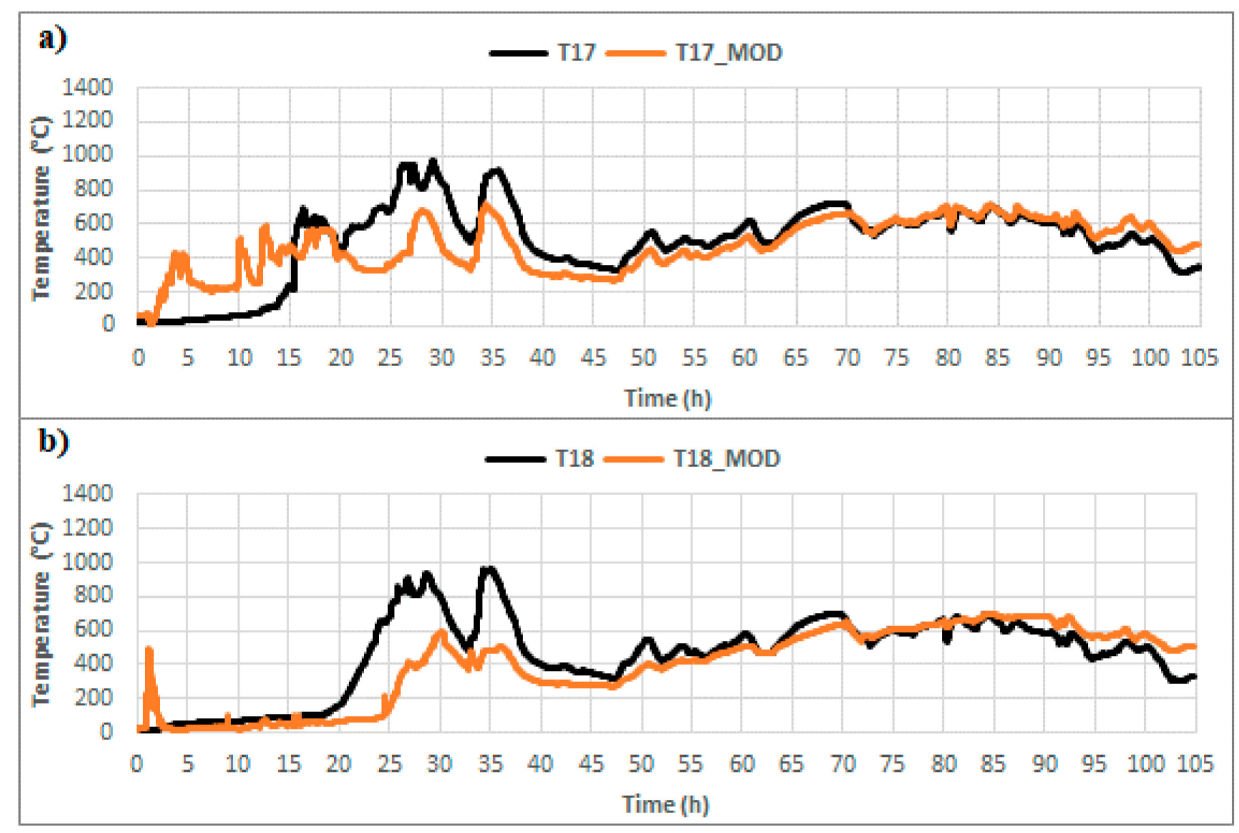

Figure 23. The measured (T) and modeled (T_MOD) temperature behavior in the second phase verification by using modified regression models, (a) temperature $T_{17},(\mathbf{b})$ temperature $T_{18}$ (Source: own elaboration).

The average calorific value for the first experiment was 1.155 and for the second experiment was 0.657 . Thus, we can say that the influence of calorific value on the modeled coal temperatures $T_{17}$ and $T_{18}$ was reduced by almost half in the second experiment. The calorific value reduction causes significant differences between the measured and modeled temperatures, especially if the temperatures are above $600{ }^{\circ} \mathrm{C}$. Syngas with the desired composition and calorific value can be produced (i.e., the transformation of coal into gas occurs) due to this temperature.

\section{Conclusions}

This described research aimed to propose regression models for modeling temperatures in the gasification channels and the coal seam gasified in the ex situ reactor. The proposed models were to contribute to developing a methodology for predicting temperatures in a gasified coal seam. Improving the prediction of these temperatures with higher accuracy makes it possible to identify places in the coal seam where coal to gas is transformed and the underground cavity is formed. The prediction of coal seam temperatures would also allow the development of methods to control the UCG process based on modeled temperatures in the coal seam.

Two experiments were performed for the proposal and verification of regression models. These experiments were differed by the volume of gasified coal and thus also in the duration of the experiment. The proposal of regression coefficients was performed on the data from the first experiment, but the verification of the proposed regression models was performed mainly on the data from the second experiment. The ability to use the 
created regression models to predict temperatures in the UCG process realized under approximately the same geological conditions, e.g., the same structure of the coal seam with the surrounding rocks, was tested. The coal model (i.e., placement of coal blocks and isolation layers) in the second experiment had the same structure as the coal model of the first experiment, where the difference was the amount of gasified coal. This coal amount affected the experiment duration, the amount of gasification agent used, and the output data obtained from the experiment.

The quality of the models was assessed by calculating the multiple coefficient of determination and the standard error of the estimate. In the first stage of the research, two model structures were proposed, i.e., multiple linear regression models for channel and coal temperatures. A more number of independent variables influencing the gasification process were considered in the first solution. The multiple coefficient of determination of the proposed regression models for channel temperatures expressed more than $96 \%$ and for coal temperatures more than $61 \%$ of the variability of the dependent variable. This solution proved to be less efficient in verifying proposed models on the data from the second experiment because it was influenced by the transmission of the error from all independent variables. The multiple coefficient of determination was ranged from 9.97 to $87.17 \%$ for channel temperatures and for coal temperatures was outside its specified range when was verified on directly measured data. Verification using also modeled temperatures showed a very low similarity between the measured and modeled temperatures.

The structure of the independent variables was optimized, and subsequently, final regression models were created under their significantly smaller number. The multiple coefficient of determination of the proposed regression models for channel temperatures expressed more than $91 \%$ and for coal temperatures more than $71 \%$ of the variability of the dependent variable. Verification of the data from the second experiment confirmed the correctness of reducing the number of independently variables by increasing its values. The stability of the coal temperatures modeling was not affected by the transition from measured to modeled data at their calculation because the value of the multiple coefficient of determination decreased only minimally (i.e., for temperature $T_{17}$ from 48.94 to $46.03 \%$ and temperature $T_{18}$ from 48.47 to $48.19 \%$ ). The results indicated the possibility of using the proposed model of channel temperatures for the first half of the generator. The prediction of coal temperatures showed a 50\% similarity of measured and modeled values, i.e., use the model only on data in the second half time of the experiment. This result was caused by lower values of the measured calorific value of syngas, mainly at the internal temperature $T_{18}$, when the regression model contained a higher value of the regression coefficient $b_{1}$. The calorific value could be influenced by the suction air at the outlet of the ex situ reactor, where a fan was placed on improving the control of the UCG process.

Low similarities of measured and modeled temperatures and thus the low quality of the proposed regression models could be caused by leaks of gasification agent through ex situ reactor cracks. We can say that there are still many options for the development of regression models for temperature prediction in the gasified coal seam, for example:

- improving the experimental process for data collection, e.g., by reducing to a minimum respectively by removing gasification agent leaks during the experiment, continuous measurement of gas composition and calorific value along the length of the ex situ reactor, etc.

- including dimensionless numbers in the regression models proposal for their application under various conditions, e.g., the Fourier number as a dimensionless time

- determination of relevant independent variables for modeling temperatures in specific places of the coal seam by extended regression analysis

Author Contributions: Conceptualization, M.D. and M.B.; methodology, M.B.; validation, M.B. and M.D.; formal analysis, J.K.; data curation, M.L., J.K. and P.F.; writing-original draft preparation, M.D. and M.B.; writing-review and editing, M.D., P.F. and M.L.; visualization, P.F. and J.K. All authors have read and agreed to the published version of the manuscript. 
Funding: This research was funded by project COGAR RFCR-CT-2013-00002, Slovak Research and Development Agency, under contract No. APVV-18-0526 and No. APVV-14-0892.

Institutional Review Board Statement: Not applicable.

Informed Consent Statement: Not applicable.

Data Availability Statement: No new data were created or analyzed in this study. Data sharing is not applicable to this article.

Acknowledgments: This work was supported by the Slovak Research and Development Agency under contract No. APVV-18-0526 and APVV-14-0892.

Conflicts of Interest: The authors declare no conflict of interest.

\section{References}

1. Bhutto, A.W.; Bazmi, A.A.; Zahedi, G. Underground coal gasification: From fundamentals to applications. Prog. Energy Combust. Sci. 2013, 39, 189-214. [CrossRef]

2. Uppal, A.A.; Bhatti, A.I.; Aamir, E.; Samar, R.; Khan, S.A. Control oriented modeling and optimization of one dimensional packed bed model of underground coal gasification. J. Process. Control 2014, 24, 269-277. [CrossRef]

3. Škvareková, E.; Tomašková, M.; Wittenberger, G.; Zeleňák, Š. Analysis of Risk Factors for Underground Coal Gasification. Manag. Syst. Prod. Eng. 2019, 27, 227-235. [CrossRef]

4. Xiao, Y.; Yin, H.; Duan, T.; Qi, H.; Zhang, Y.; Jolfaei, A.; Xia, K. An Intelligent prediction model for UCG state based on dual-source LSTM. Int. J. Mach. Learn. Cybern. 2020. [CrossRef]

5. Canbaz, E.D.; Gur, M. Prediction of underground coal gasification performance of Turkish lignite reserves using stochiometric equilibrium model. J. Therm. Sci. Technol. 2020, 40, 195-205. [CrossRef]

6. Otto, C.; Kempka, T. Synthesis Gas Composition Prediction for Underground Coal Gasification Using a Thermochemical Equilibrium Modeling Approach. Energies 2020, 13, 1171. [CrossRef]

7. Janoszek, T.; Masny, W. CFD Simulations of Allothermal Steam Gasification Process for Hydrogen Production. Energies 2021, 14, 1532. [CrossRef]

8. Jowkar, A.; Sereshki, F.; Najafi, M. A new model for evaluation of cavity shape and volume during Underground Coal Gasification process. Energy 2018, 148, 756-765. [CrossRef]

9. Khan, M.M.; Mmbaga, J.; Shirazi, A.; Trivedi, J.; Liu, Q.; Gupta, R. Modelling Underground Coal Gasification-A Review. Energies 2015, 8, 12603-12668. [CrossRef]

10. Najafi, M.; Jalali, S.M.E.; KhaloKakaie, R.; Forouhandeh, F. Prediction of cavity growth rate during underground coal gasification using multiple regression analysis. Int. J. Coal Sci. Technol. 2015, 2, 318-324. [CrossRef]

11. Gur, M.; Canbaz, E.D. Analysis of syngas production and reaction zones in hydrogen oriented underground coal gasification. Fuel 2020, 269, 117331. [CrossRef]

12. Mandal, R.; Maity, T.; Chaulya, S.K.; Prasad, G.M. Laboratory investigation on underground coal gasification technique with real-time analysis. Fuel 2020, 275, 117865. [CrossRef]

13. Kapusta, K.; Wiatowski, M.; Stańczyk, K.; Zagorščak, R.; Thomas, H.R. Large-scale Experimental Investigations to Evaluate the Feasibility of Producing Methane-Rich Gas (SNG) through Underground Coal Gasification Process. Effect of Coal Rank and Gasification Pressure. Energies 2020, 13, 1334. [CrossRef]

14. Andrianopoulos, E.; Korre, A.; Durucan, S. Chemical Process Modelling of Underground Coal Gasification and Evaluation of Produced Gas Quality for End Use. Energy Procedia 2015, 76, 444-453. [CrossRef]

15. Yang, L. The Dynamic Temperature Field of Two-Stage Underground Coal Gasification (UCG). Energy Sources Part A 2006, 28, 667-680. [CrossRef]

16. Xin, L.; Wang, Z.; Huang, W.; Kang, G.; Lu, X.; Zhang, P.; Wang, J. Temperature field distribution of burnt surrounding rock in UCG stope. Int. J. Min. Sci. Technol. 2014, 24, 573-580. [CrossRef]

17. Kostúr, K.; Laciak, M.; Durdán, M. Some Influences of Underground Coal Gasification on the Environment. Sustainability 2018, 10, 1512. [CrossRef]

18. Luo, Y.; Margaretha, C.S.D. Comparison of UCG cavity growth with CFD model predictions. In Proceedings of the 7th International Conference on CFD in Minerals and Process Industries, Melbourne, Australia, 9-11 December 2009; CSIRO: Melbourne, Australia, 2009.

19. Janoszek, T.; Sygała, A.; Bukowska, M. CFD Simulation of Temperature Variation in Carboniferous Rock Strata during UCG. J. Sustain. Min. 2013, 12, 34-44. [CrossRef]

20. Otto, C.; Kempka, T. Thermo-mechanical Simulations Confirm: Temperature-dependent Mudrock Properties are Nice to have in Far-field Environmental Assessments of Underground Coal Gasification. Energy Procedia 2015, 76, 582-591. [CrossRef]

21. Kafle, R.C.; Pokhrel, K.P.; Khanal, N.; Tsokos, C.P. Differential equation model of carbon dioxide emission using functional linear regression. J. Appl. Stat. 2018, 46, 1246-1259. [CrossRef] 
22. Motiee, H.; Ghasemnejad, S. Prediction of pipe failure rate in Tehran water distribution networks by applying regression models. Water Supply 2018, 19, 695-702. [CrossRef]

23. Hadavandi, E.; Hower, J.C.; Chelgani, S.C. Modeling of gross calorific value based on coal properties by support vector regression method. Modeling Earth Syst. Environ. 2017, 3, 37. [CrossRef]

24. Xu, L.; Cheng, Y.; Yin, R.; Zhang, Q. Comparative study of regression modeling methods for online coal calorific value prediction from flame radiation features. Fuel 2015, 142, 164-172. [CrossRef]

25. Gou, X.; Zhou, J.H.; Liu, J.Z.; Cen, K.F. Research on regression model of pulverized coal ignition temperature. Energy Educ. Sci. Technol. Part A 2011, 28, 143-150.

26. Chelgani, S.C.; Hower, J.C.; Jorjani, E.; Mesroghli, S.; Bagherieh, A.H. Prediction of coal grindability based on petrography, proximate and ultimate analysis using multiple regression and artificial neural network models. Fuel Process. Technol. 2008, 89, 13-20. [CrossRef]

27. Krzemien, A. Fire risk prevention in underground coal gasification (UCG) within active mines: Temperature forecast by means of MARS models. Energy 2019, 170, 777-790. [CrossRef]

28. Kapusta, K.; Stańczyk, K. Chemical and toxicological evaluation of underground coal gasification (UCG) effluents. The coal rank effect. Ecotoxicol. Environ. Saf. 2015, 112, 105-113. [CrossRef]

29. Shrestha, A.K.; Basnet, N. The Correlation and Regression Analysis of Physicochemical Parameters of River Water for the Evaluation of Percentage Contribution to Electrical Conductivity. J. Chem. 2018, 2018, 1-9. [CrossRef]

30. Huang, L.; Chen, J.C. A Multiple Regression Model to Predict In-process Surface Roughness in Turning Operation via Accelerometer. J. Ind. Technol. 2001, 17, 1-8.

31. Tavallali, P.; Razavi, M.; Brady, S. A non-linear data mining parameter selection algorithm for continuous variables. PLoS ONE 2017, 12, e0187676. [CrossRef] [PubMed]

32. Kačur, J.; Laciak, M.; Durdán, M.; Flegner, P. Utilization of Machine Learning Method. In Proceedings of the 18th International Carpathian Control Conference (ICCC), Sinaia, Romania, 28-31 May 2017.

33. Škvareková, E.; Taušová, M.; Seňová, A.; Wittenberger, G.; Novaková, J. Statistical Evaluation of Quantities Measured in the Detection of Soil Air Pollution of the Environmental Burden. Appl. Sci. 2021, 11, 3294. [CrossRef]

34. Bazaluk, O.; Lozynskyi, V.; Falshtynskyi, V.; Saik, P.; Dychkovskyi, R.; Cabana, E. Experimental Studies of the Effect of Design and Technological Solutions on the Intensification of an Underground Coal Gasification Process. Energies 2021, 14, 4369. [CrossRef]

35. Zagorščak, R.; Sadasivam, S.; Thomas, H.R.; Stańczyk, K.; Kapusta, K. Experimental study of underground coal gasification (UCG) of a high-rank coal using atmospheric and high-pressure conditions in an ex-situ reactor. Fuel 2020, 270, 117490. [CrossRef]

36. Durdán, M.; Terpák, J.; Kačur, J.; Laciak, M.; Flegner, P. Modeling of material balance from the experimental UCG. Acta Polytech. 2020, 60, 391-399. [CrossRef]

37. Aczel, A. Complete Business Statistics; Irwin: Homewood, IL, USA, 1989.

38. Montgomery, D. Introduction to Statistical Quality Control; Wiley: Hoboken, NJ, USA, 2009.

39. Rencher, A. Methods of Multivariate Analysis; Wiley: New York, NY, USA, 2002.

40. Hair, J.F.; Anderson, R.E.; Black, W.C.; Tatham, R.L. Multivariate Data Analysis with Readings; Prentice Hall: Englewood Cliffs, NJ, USA, 1995. 